\title{
O crescimento econômico dos municípios mineiros tem sido pró-pobre? \\ Uma análise para o período 1991-2000
}

Guilherme Mendes Resende

Pesquisador do Instituto de Pesquisa Econômica Aplicada (IPEA)

\section{Palavras-chave}

crescimento pró-pobre, desigualdade de renda, pobreza.

\section{Classificação JEL D31.}

Key words

pro-poor growth, income inequality, poverty.

JEL Classification D31.

\section{Resumo}

O principal objetivo deste artigo é analisar a relação entre crescimento econômico e pobreza do ponto de vista qualitativo. Em outras palavras, busca-se analisar em que medida o crescimento econômico dos municípios mineiros mostrou-se um mecanismo relativamente eficaz de combate à pobreza do Estado entre 1991 e 2000 . Os resultados revelaram a diversidade do território mineiro. Foram encontradas regiões com uma boa qualidade de crescimento onde existe maior elasticidade "pobreza-crescimento", ou seja, uma relativa maior capacidade de reduzir a proporção de pobres para uma determinada taxa de crescimento. Esse resultado é explicado não apenas pela sua menor intensidade de pobreza, mas também pelo relativo maior impacto do crescimento econômico sobre os mais pobres, isto é, pela "qualidade" do crescimento municipal. Por outro lado existem regiões com menor elasticidade "pobrezacrescimento". Por fim, foram analisadas as características socioeconômicas dos municípios pertencentes a cada um dos quatro padrões de crescimento verificados.

\section{Abstract}

The main goal of this paper is to analyze the relation between economic growth and poverty from a qualitative point of view. In other words, it seeks to analyze how economic growth in Minas Gerais' municipalities proved to be an efficient mechanism of poverty reduction between 1991-2000. Results showed diversity in the state of Minas Gerais. There are regions with good quality of economic growth, where "poverty-growth" elasticity is high; that is, there is a greater capacity to reduce poverty for a determined growth rate. This result is explained not only for lower intensity of poverty, but also for greater impact of economic growth on the poor, that is, "quality" of city growth. On the other hand, there are regions with low quality of economic growth where "poverty-growth" elasticity is low. Finally, trends of socioeconomic characteristics of each of the four economic growth classes were analyzed. 


\section{1_Introdução}

Este trabalho tem o intuito de investigar a relação entre crescimento econômico, desigualdade de renda e pobreza ao longo do território mineiro, suas macrorregiões e seus municípios. Com base nas informações dos Censos Demográficos de 1991 e 2000, analisa-se a "qualidade" do crescimento econômico no sentido de seu impacto na pobreza.

A relação entre crescimento econômico, desigualdade de renda e pobreza encontra-se no centro do debate de desenvolvimento econômico. $\mathrm{O}$ debate sobre o tema foi, e ainda é, muito polêmico. Segundo Shorrocks e Hoven (2005), de 1950 até o início dos anos 1970, o debate enfatizou o provável trade-off entre crescimento econômico e desigualdade de renda. ${ }^{1}$ Isso é derivado da hipótese da curva de Kuznets (hipótese do U-invertido), a qual afirma que a desigualdade aumenta durante uma fase inicial de desenvolvimento e, então, declina após um nível crucial de desenvolvimento (Kuznets, 1955). A idéia do trade-off entre crescimento econômico e desigualdade de renda é extensamente tratada na literatura. ${ }^{2}$ A partir dos anos 1970, há o reconhecimento, tanto por parte das instituições voltadas para o financiamento do desenvolvimento (por exemplo, Banco Mundial e Organização das Nações Unidas) quanto pelo meio acadêmico, de que o crescimento econômico não estava solucionando questões básicas relativas às desigualdades de renda e à pobreza. Em conseqüência dessa constatação, a redução da pobreza tornou-se o objetivo principal, como se pode evidenciar em estudos das Nações Unidas e Banco Mundial [ver, por exemplo, PNUD (2005) e Word Bank (2000)]. Não se tratava, porém, de priorizar políticas assistencialistas. Como bem salienta Rocha (2005), a questão central era repensar o processo de crescimento econômico, de modo a considerar explicitamente os objetivos de redução da desigualdade e da pobreza, integrando subgrupos mais pobres da população no processo de crescimento econômico e usufruto de seus resultados.

Com o presente estudo, busca-se analisar em que medida o crescimento econômico dos municípios mineiros tem se revelado um mecanismo relativamente eficaz de combate à pobreza do Estado. Uma maneira de se estudar essa questão é analisar o crescimento da renda (domiciliar) per capita dos mais pobres em relação ao crescimento da renda média de toda a população. Caso o crescimento da renda per capita dos pobres for maior que o da renda per $c a-$ pita média, tem-se um crescimento econômico pró-pobre (Son, 2004). Assim, para o período 1991-2000, a principal questão a ser respondida por esse trabalho é: o crescimento econômico dos municípios mineiros tem sido pró-pobre?
Em Shorrocks e Hoven (2005) temos um bom relato do debate sobre crescimento econômico, desigualdade de renda e pobreza.

2 Ver, por exemplo, Alesina e Rodrik (1994), Person e Tabellini (1994) e Galor e Zeira (1993). 
Apesar da importância de informações nesse sentido para a elaboração de políticas públicas mais eficazes no combate à pobreza de Minas Gerais, nenhum estudo específico para os municípios mineiros ainda foi feito. Os estudos até agora realizados utilizam dados estaduais (Ribeiro et al., 2004), das microrregiões do Nordeste (Silveira Neto, 2005) e dos municípios do Nordeste (Gonçalves e Silveira Neto, 2007). Em relação a Minas Gerais, utilizando-se dados municipais dos Censos Demográficos de 1991 e 2000, este trabalho pretende, ao menos em parte, preencher essa lacuna. Vale ainda destacar que, em um Estado com municípios e regiões tão díspares do ponto de vista socioeconômico, a investigação apenas dos municípios mineiros possibilita uma análise mais precisa das relações entre crescimento econômico, desigualdade de renda e pobreza. Tal investigação tem o intuito de evidenciar que os padrões de crescimento podem não ser necessariamente os mesmos entre municípios e regiões de Minas Gerais, necessitando-se, dessa forma, que estratégias distintas sejam adotadas para o combate à pobreza no Estado.

Inicialmente, este estudo faz uma discussão sobre os diferenciais nas taxas de crescimento econômico das macrorregiões mineiras e dos municípios mineiros e a evolução da pobreza e da desigualdade de renda no período 1991-2000. Em seguida, valendo-se de dados dos municípios mineiros, são fornecidas evidências a respeito da sensibilidade da pobreza das macrorregiões mineiras ao crescimento econômico (elasticidade "pobreza-crescimento"), evidências essas que são comparadas com aquelas obtidas, por estudos anteriores, para as macrorregiões do País. A seguir, os municípios mineiros são utilizados para identificar se a menor reação da pobreza ao crescimento econômico encontrada para algumas macrorregiões mineiras é explicada pelo menor crescimento relativo da renda per capita dos mais pobres, caso em que o crescimento seria não pró-pobre (Son, 2004). Por fim, algumas características socioeconômicas dos municípios também são analisadas, verificando se os municípios identificados com um padrão de crescimento pró-pobre têm características diferentes dos demais municípios.

O presente trabalho está dividido em cinco seções. A seguir, na seção 2, discute-se a dinâmica das taxas de crescimento econômico das macrorregiões e municípios mineiros e a evolução da pobreza e da desigualdade de renda entre 1991 e 2000. A seção 3 apresenta a elasticidade "pobrezacrescimento" para as macrorregiões mineiras e como o crescimento econômico tem beneficiado diferentemente os mais pobres e o universo da população nos municípios mineiros, isto é, uma análise se o crescimento tem sido pró-pobre. Na quarta seção, é feita uma análise das características 
socioeconômicas dos municípios, dividindo-os por padrões de "qualidade" de crescimento econômico. Por fim, as conclusões são feitas na seção cinco.

\section{Dinâmica do crescimento econômico e a evolução da pobreza em Minas Gerais entre 1991-2000}

Nesta seção são discutidas questões referentes à evolução da pobreza, da desigualdade de renda e aos diferenciais nas taxas de crescimento econômico dos municípios de Minas Gerais no período 1991-2000. A análise é empreendida tendo como área de análise os municípios do Estado de Minas Gerais, além de números agregados para as macrorregiões e o Estado. Em 2000, o Estado de Minas Gerais era composto por 853 municípios $^{3}$ divididos em 10 macrorregiões de planejamento. ${ }^{4}$

Primeiramente, no Mapa 1 do Anexo, evidenciam-se as dez macrorregiões do Estado de Minas Gerais e os municípios com mais de 100 mil habitantes. Como se pode verificar, a macrorregião Central é a mais populosa, compreendendo a capital Belo Horizonte com cerca de 2 milhões e 200 mil habitantes no ano de 2000.

Como já salientado na introdução, o foco deste artigo busca captar a relação entre crescimento econômico do Estado de Minas Gerais e seus benefícios para os in- divíduos em diferentes condições econômicas. Cabe aqui salientar que a análise a ser desenvolvida privilegia a pobreza do ponto de vista da renda. Embora pobreza seja, reconhecidamente, uma síndrome multidimensional caracterizada por carências diversas, a abordagem da renda é essencial para caracterizar pobreza no contexto de uma sociedade moderna que apresenta o grau de complexidade urbana como a maioria dos municípios de Minas Gerais. Na verdade, em sociedades desse tipo, a maioria das necessidades no âmbito do consumo privado é atendida através do mercado, estando o nível de bem-estar estreitamente associado ao nível de renda (Rocha, 1995). Utilizar a abordagem da renda implica recorrer a um parâmetro de valor, a linha de pobreza, para distinguir pobres de não-pobres no conjunto da população: pobres são aqueles cuja renda domiciliar per capita é inferior ao valor da linha de pobreza relevante para determinado tempo e local; nãopobres são os demais. A escolha das linhas de pobreza empregadas neste trabalho explica-se pelo objetivo de utilizar linhas de pobreza disponibilizadas ao grande público (por exemplo, no site do IPEADATA) e pelo seu emprego em estudos similares (por exemplo, em Silveira Neto, 2005). Ademais, a utilização dos Censos Demográficos de 1991 e 2000 permitiu uma desagregação espacial em nível municipal que é o foco deste estudo.

\footnotetext{
Com o processo de

Com o processo de

divisões municipais ocorrido durante a década de 90 , o número de municípios brasileiros passou de 4.491 em 1991 para 5.507 em 2000. Para viabilizar a comparação dos dados entre esses dois períodos, foi realizado um trabalho de compatibilização dos dados de 1991, reproduzindo nesse ano a malha municipal de 2000 [ver Ipea, Pund e FJP (2003) Atlas do Desenvolvimento Humano no Brasil].

4 A divisão do território de Minas Gerais, adotada oficialmente pelo governo estadual, estabelece dez Regiões de Planejamento, listadas a seguir, em ordem alfabética: Alto Paranaíba, Central, Centro-Oeste de Minas, Jequitinhonha/Mucuri, Zona da Mata, Noroeste de Minas, Norte de Minas, Rio Doce, Sul de Minas e Triângulo Mineiro.
} 
5 Linha de indigência: percentual de pessoas com renda domiciliar per capita abaixo de $\mathrm{R} \$ 37,75$ (equivalente a $1 / 4$ salário mínimo de agosto de 2000).

6 Linha de pobreza: percentual de pessoas com renda domiciliar per capita abaixo de $\mathrm{R} \$ 75,50$

(equivalente a $1 \frac{1}{2}$ salário mínimo de agosto de 2000).
Apesar da não-utilização do conceito multidimensional da pobreza neste artigo, vale destacar a contribuição da literatura sobre pobreza não focada em renda exclusivamente. A discussão da multidimensionalidade da pobreza está ligada à abordagem das capacitações, desenvolvida pelo prêmio Nobel de Economia, Professor Amartya Sen. Segundo essa vertente, a pobreza é definida relativamente à capacidade dos indivíduos de exercerem suas liberdades bem como de fazerem respeitar seus direitos. Enfatiza-se não apenas os direitos sociais (saúde, educação, moradia etc.), mas também os direitos civis e políticos (Sen, 2000). Portanto, o conceito de pobreza multidimensional compreende privações não só de renda, mas também de capacidades e acesso a bens, serviços e direitos. Por sua vez, o caráter multidimensional da pobreza leva à necessidade de um indicador que tenha uma correspondente abordagem multidimensional. No Brasil, trabalhos recentes têm abordado esse tema (Lopes et al., 2003; Barros e Carvalho, 2006; Bangolin e Ávila, 2006). Nesses trabalhos são construídos indicadores que reconhecem que a condição de pobreza dos indivíduos não pode ser precisamente auferida unicamente com base no indicador renda. Entretanto, mesmo sabendo-se da amplitude e da importância de se tratar a pobreza multidimensionalmente, $\mathrm{O}$ presente artigo limita-se a discutir a pobreza unidimensional.
Inicialmente, na Tabela 1, são apresentados alguns indicadores de pobreza e crescimento econômico para as macrorregiões de Minas Gerais e demais regiões do Brasil. Ainda que possa sobre-estimar os níveis de pobreza de alguma macrorregião mineira ou região brasileira, onde a pobreza é predominantemente rural (por exemplo, o Norte de Minas e o Nordeste brasileiro), em virtude da utilização de linhas de pobreza e indigência comuns, os valores permitem verificar as diferenças nos percentuais de indigentes ${ }^{5}$ e pobres ${ }^{6}$ presentes no Estado de Minas Gerais se comparado com todas as regiões da Federação.

Em 2000, Minas Gerais tinha cerca de $30 \%$ de sua população em estado de pobreza. De acordo com a Tabela 1, apesar de apresentar um percentual próximo da média nacional $(32,9 \%)$, ao se analisar Minas Gerais a partir de suas macrorregiões, encontram-se regiões com níveis de pobreza bem distintos. A população da Zona da Mata é composta por $30,3 \%$ de pobres (próximo à média nacional, 32,9\%), e as regiões do Alto-Paranaiba, Centro-Oeste de Minas e do Sul de Minas têm, respectivamente, 19,5, 19 e 20,4\% de suas populações compostas por pobres (semelhante às regiões Sudeste, 19,7\%, e Sul, 20,5\% do Brasil). Já as macrorregiões mineiras do Vale do Jequitinhonha/Mucuri e Norte de Minas apresentam 61 e $58 \%$ de pobres, respectivamen- 
te (aproximadamente os mesmos valores da região Nordeste, 56,7\%). A região Central $(24,4 \%)$ de Minas Gerais tem um percentual de pobres bem próximo ao do Centro-Oes- te do Brasil (25,4\%). Ademais, observa-se que o Triângulo Mineiro tem um menor percentual de pobres $(16,7 \%)$ se comparado a qualquer região mineira ou brasileira.

Tabela 1_ Pobreza e taxa de crescimento da renda "per capita" nas regiões do Brasil e nas dez macrorregióes de Minas Gerais - 1991 a 2000

\begin{tabular}{|c|c|c|c|c|c|}
\hline Estado & $\begin{array}{c}\text { Percentual } \\
\text { de indigentes } \\
1991\end{array}$ & $\begin{array}{c}\text { Percentual } \\
\text { de indigentes } \\
2000\end{array}$ & $\begin{array}{c}\text { Percentual } \\
\text { de pobres } \\
1991\end{array}$ & $\begin{array}{c}\text { Percentual } \\
\text { de pobres } \\
2000\end{array}$ & $\begin{array}{c}\text { Taxa de } \\
\text { crescimento } \\
\text { da renda } \\
\text { "per capita" }\end{array}$ \\
\hline NORTE & 27,1 & 26,3 & 52,6 & 49,3 & 17,1 \\
\hline NORDESTE & 40,6 & 32,3 & 67,1 & 56,7 & 35,3 \\
\hline Alto Paranaíba & 11,0 & 5,2 & 35,0 & 19,5 & 48,4 \\
\hline Central & 13,3 & 9,3 & 33,5 & 24,4 & 32,2 \\
\hline Centro-Oeste de Minas & 13,7 & 5,5 & 39,6 & 19,9 & 58,6 \\
\hline Jequitinhonha/Mucuri & 44,1 & 34,6 & 72,5 & 61,4 & 40,5 \\
\hline Noroeste de Minas & 23,9 & 15,8 & 53,4 & 37,5 & 70,4 \\
\hline Norte de Minas & 40,3 & 33,1 & 69,5 & 58,0 & 38,6 \\
\hline Rio Doce & 29,0 & 18,6 & 55,2 & 40,1 & 53,1 \\
\hline Sul de Minas & 12,5 & 5,9 & 36,4 & 20,4 & 49,0 \\
\hline Triângulo Mineiro & 6,3 & 5,0 & 23,1 & 16,7 & 37,0 \\
\hline Zona da Mata & 23,4 & 11,4 & 49,0 & 30,3 & 51,3 \\
\hline Minas Gerais & 19,7 & 12,6 & 43,3 & 29,8 & 42,9 \\
\hline SUDESTE & 9,6 & 8,2 & 24,3 & 19,7 & 24,3 \\
\hline SUL & 12,1 & 7,9 & 30,8 & 20,5 & 41,3 \\
\hline CENTRO-OESTE & 12,0 & 9,7 & 32,7 & 25,4 & 33,7 \\
\hline BRASIL & $20,3$. & 16,4 . & 40,1 & 32,9 & $29,1$. \\
\hline
\end{tabular}

Fonte: Elaboração própria com base em dados dos Censos Demográficos de 1991 e 2000.

Obs.: Linhas de pobreza e indigência de $\mathrm{R} \$ 75,50$ (equivalente a 1/2 salário mínimo de agosto de 2000) e R \$ 37,75

(equivalente a $1 / 4$ salário mínimo de agosto de 2000 ), respectivamente. 
7 Mede o grau de

desigualdade existente na distribuição de indivíduos segundo a renda domiciliar per capita. Seu valor varia de 0 , quando não há desigualdade (a renda de todos os indivíduos tem o mesmo valor), a 1 , quando a desigualdade é máxima (apenas um indivíduo detém toda a renda da sociedade, e a renda de todos os outros indivíduos é nula).
Outro fato digno de nota é a evolução da desigualdade de renda no período. No Gráfico 1, apresenta-se um indicador de desigualdade renda para as dez macrorregiões e para o Estado de Minas Gerais, o índice de Gini. No que concerne ao Estado de Minas Gerais, a desigualdade de renda aumentou entre 1991 e 2000, visto que o índice de Gini ${ }^{7}$ aumentou de 0,61 para 0,62.

Se for analisada a evolução da desigualdade de renda nas macrorregiões de Minas Gerais, observa-se que em oito dessas regiões houve elevações na desigualdade de renda. Entretanto, esses incrementos na desigualdade de renda vieram acompanhados de diferentes performances das taxas de crescimento da renda per capita e da evolução da pobreza no período. Por exemplo, no Norte de Minas onde se verificou uma pequena queda da pobreza (em 2000, a região ainda tinha $58 \%$ de pessoas pobres) e um crescimento da renda per capita de 38,6\% entre 1991-2000 (o terceiro menor crescimento econômico entre as regiões do Estado), acompanhou-se uma elevação do índice de Gini de 0,55 para 0,60. Já o Noroeste de Minas, onde também se observa um aumento na desigualdade de renda (o Gini sobe de 0,56 para 0,63 entre 1991-2000), apresentou o maior percentual de crescimento da renda per capita do Estado (cerca de $70 \%$ no período), obtendo uma queda de cerca de 16 pontos percentuais no percentual de pobres.

\section{Gráfico 1_ Índice de Gini (Indicador de desigualdade de renda) - 1991 e 2000}

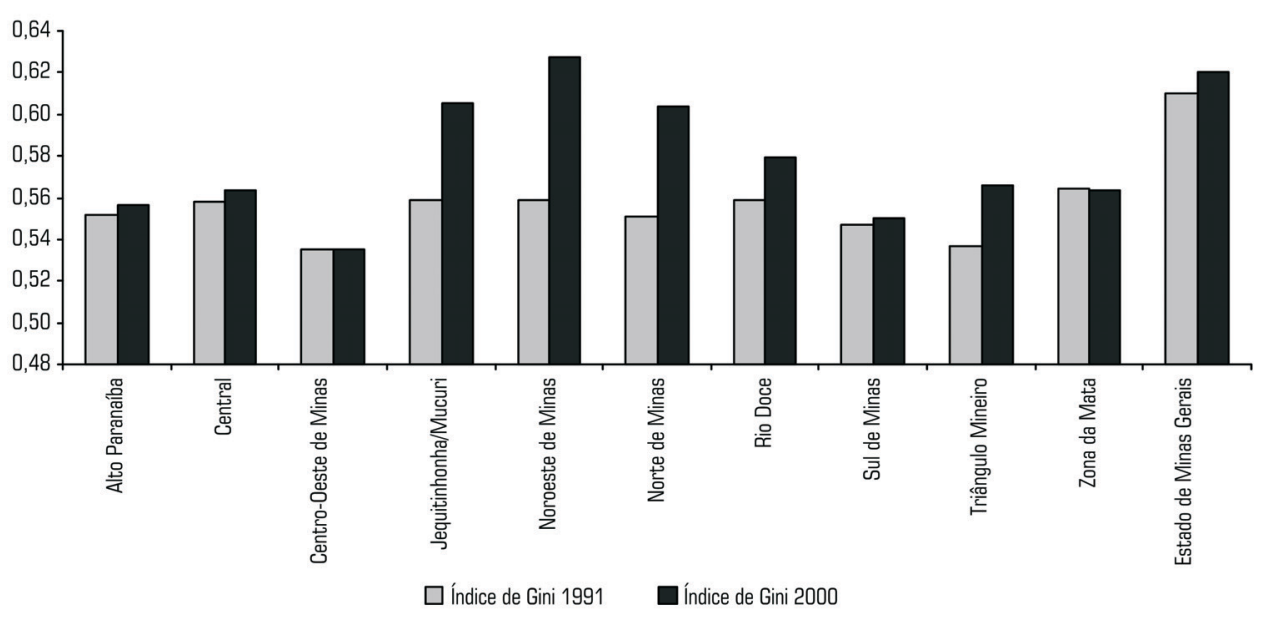

Fonte: Elaboração própria com base em dados municipal e estadual do IPEADATA. 
Por outro lado, o Centro-Oeste de Minas é uma região onde se verificou estabilidade na desigualdade de renda no período, obtendo a maior redução no percentual de pobres (cerca de 20 pontos percentuais) e a segunda maior taxa de crescimento econômico (58,6\% entre 1991 2000). Um padrão semelhante é encontrado na Zona da Mata, onde a desigualdade de renda também se manteve estável no período, obtendo a segunda maior redução no percentual de pobres (cerca de 19 pontos percentuais) e uma taxa de crescimento econômico de 51,3\% entre 19912000. A análise descritiva das regiões mineiras aponta que a relação entre crescimento econômico e desigualdade de renda não é clara. ${ }^{8}$

Como pode ser percebido pela observação das Tabelas 1 e 2, embora o crescimento da renda per capita das macrorregiões Noroeste (crescimento da renda per capita de 70,4\% no período 1991-2000) e do Rio Doce $(53,1 \%)$ ter sido mais vigoroso que aquele apresentado pelo Estado como um todo $(42,9 \%)$, não foi suficiente para eliminar suas sobre-representações no total de indigentes e pobres do Estado. Tais sobre-representações foram obtidas a partir do cálculo entre a participação da população da macrorregião na população do Estado e a participação dos indigentes e pobres da macrorregião no total de indigentes e pobres do Estado. Outras duas macrorregiões, Jequitinhonha/Mucuri e Norte de Minas, também apresentaram uma sobre-representação no total de indigentes e pobres do Estado. Por exemplo, em 2000, a região do Jequitinhonha/Mucuri tinha 5,5\% da população do Estado e cerca do dobro $(11,2 \%)$ dos pobres do Estado. Entre 1991 e 2000, tal sobre-representação teve leve aumento.

Um quadro ainda mais detalhado das condições de pobreza e das possibilidades de sua redução pode ser obtido reduzindo-se o grau de agregação espacial de macrorregião para município do Estado de Minas Gerais, o que permite considerar situações bastante distintas dentro do Estado. A partir da divisão espacial das macrorregiões em 853 municípios, os Mapas 2 e 3 do Anexo, permitem verificar novas evidências quanto às condições e à dinâmica da pobreza no Estado de Minas Gerais. Nos mapas, é possível observar, de imediato, que os $12,6 \%$ de indigentes e $29,8 \%$ de pobres da população de Minas Gerais, em 2000, apontados na Tabela 1 , encobrem importantes diferenças intra-estadual.

\footnotetext{
Uma evidência empírica comum na literatura recente é que alterações na desigualdade dos países têm praticamente correlação zero com as taxas de crescimento econômico; ver, por exemplo, Ravallion e Chen (1997), Ravallion (2001), Dollar e Kraay (2002).
} 
Tabela 2_Participação das macrorregiões de Minas Gerais no número de pobres e na população do próprio Estado (\%)

\begin{tabular}{|c|c|c|c|c|c|c|}
\hline \multirow[b]{2}{*}{ Macrorregião } & \multicolumn{3}{|c|}{1991} & \multicolumn{3}{|c|}{2000} \\
\hline & $\begin{array}{c}\text { Participação } \\
\text { no número } \\
\text { de indigentes }\end{array}$ & $\begin{array}{l}\text { Participação } \\
\text { no número } \\
\text { de pobres }\end{array}$ & $\begin{array}{l}\text { Participação } \\
\text { na população }\end{array}$ & $\begin{array}{c}\text { Participação } \\
\text { no número } \\
\text { de indigentes }\end{array}$ & $\begin{array}{l}\text { Participação } \\
\text { no número } \\
\text { de pobres }\end{array}$ & $\begin{array}{l}\text { Participação } \\
\text { na população }\end{array}$ \\
\hline Alto Paranaíba & 1,8 & 2,6 & 3,3 & 1,3 & 2,1 & 3,3 \\
\hline Central & 22,5 & 25,9 & 33,4 & 25,8 & 28,6 & 35,1 \\
\hline Centro-Oeste de Minas & 3,8 & 5,0 & 5,5 & 2,4 & 3,7 & 5,5 \\
\hline Jequitinhonha/Mucuri & 13,8 & 10,3 & 6,2 & 14,9 & 11,2 & 5,5 \\
\hline Noroeste de Minas & 2,3 & 2,4 & 1,9 & 2,3 & 2,3 & 1,9 \\
\hline Norte de Minas & 17,6 & 13,9 & 8,6 & 21,7 & 16,1 & 8,3 \\
\hline Rio Doce & 13,7 & 11,8 & 9,3 & 12,5 & 11,5 & 8,6 \\
\hline Triângulo Mineiro & 2,2 & 3,7 & 6,9 & 2,8 & 4,0 & 7,2 \\
\hline Zona da Mata & 13,9 & $13,3$. & 11,7 & 10,1 & 11,5 & 11,4 \\
\hline
\end{tabular}

No Mapa 2 do Anexo, pode-se anotar que o percentual de indigência municipal em 1991 está entre 3,1 a 76,0\%. Em 2000 , essa variação diminui, ficando entre 1,8 e $65,0 \%$. Observa-se claramente grande concentração de municípios com um maior percentual de indigentes nas macrorregiões do Norte de Minas, Jequitinhonha/Mucuri e Rio Doce. Municípios com elevados percentuais de indigentes também podem ser encontrados em macrorregiões com menores percentuais de indigentes, como as macrorregiões Central e Zona da Mata.
No Mapa 3 do Anexo, verifica-se que o percentual de pobres por município em 1991 está entre 14,1 a 92,3\%. Em 2000, essa variação diminuiu, ficando entre 8,9 e 85,1\%. Pode-se verificar, como no caso do percentual de indigentes, a existência de uma grande concentração de municípios com maior percentual de pobres nas macrorregiões do Norte de Minas, Jequitinhonha/Mucuri e Rio Doce. Além disso, observa-se que, em 2000, 175 municípios (20\% do total) têm um percentual de pobres acima de $61,4 \%$ (percentual esse verificado para macrorregião do Jequitinhonha/Mucuri, que tem o maior percentual de pobres de Minas Gerais). 
Com base nessas evidências, podemse fazer ao menos duas considerações sobre a relação crescimento econômico e pobreza nos municípios do Estado de Minas Gerais. Em alguns municípios a rigidez em relação à redução da pobreza pode ser explicada potencialmente, ao menos em parte, pelos níveis bastante intensos da pobreza (pobres distantes da renda correspondente àquela da linha de pobreza) verificados em alguns municípios, o que exigiria taxas bastante elevadas de crescimento para diminuição dos níveis de pobreza. Entretanto, é importante considerar outra possibilidade: o relativo menor impacto do crescimento econômico na renda dos mais pobres. A próxima seção do trabalho investiga essas possibilidades; em outras palavras, analisa-se se o crescimento econômico tem sido pró-pobre ou não.

\section{3_Evidências do crescimento pró-pobre para Minas Gerais}

Após a descrição, na seção anterior, das condições de pobreza e crescimento econômico de Minas Gerais no período 19912000, empreende-se nesta seção a análise do crescimento pró-pobre. Mas quando o crescimento é considerado pró-pobre? Existem duas definições diferentes de crescimento pró-pobre na literatura recente e nas discussões de políticas públi- cas (Ravallion, 2004). A primeira define crescimento pró-pobre como aquele crescimento que reduz as taxas de pobreza (Ravallion e Chen, 2003). Essa definição não considera a questão da distribuição de renda diretamente. Já pela segunda definição, para o crescimento ser considerado pró-pobre, a taxa de crescimento da renda dos pobres tem de ser maior que a taxa de crescimento da renda da população como um todo (White e Anderson, 2000; Kakwani e Pernia, 2000; Son, 2004). Nessa definição, o crescimento própobre está diretamente associado a uma diminuição na desigualdade de renda. ${ }^{9}$

A seguir, as duas noções de crescimento econômico são consideradas. Como poderá se observar, existe grande vinculação entre as duas noções quando são analisados os resultados referentes aos municípios de Minas Gerais no período 1991 a 2000. Vale ressaltar a importância da segunda definição (Son, 2004), visto que esta leva em conta, diretamente, a questão da desigualdade de renda em busca da redução da pobreza. Em um país onde a desigualdade de renda é uma das maiores do mundo, ${ }^{10}$ necessariamente, as políticas públicas que visem ao crescimento econômico e, por conseguinte, à redução da pobreza, devem ser pensadas de uma maneira que o crescimento econômico seja acompanhado de uma redução na desigualdade de renda. ${ }^{11}$
Para uma discussão mais detalhada, ver Ravallion (2004) e Lopez (2004).

10 Por exemplo, em 2003, o Brasil foi o oitavo país em desigualdade de renda (índice de Gini foi de 0,6), atrás apenas da latina-americana Guatemala, e dos africanos Suazilândia, República Centro-Africana, Serra Leoa, Botsuana, Lesoto e Namíbia, segundo o coeficiente de Gini, parâmetro internacionalmente usado para medir a concentração de renda.

11 De fato, as evidências mostram que, para países com alta desigualdade de renda, o crescimento econômico é um instrumento fraco contra a pobreza a menos que esse crescimento venha acompanhado de uma diminuição da desigualdade de renda (Ravallion, 2004). 
"

12 Vale destacar que o método de mínimos quadrados ordinários (MQO) foi utilizado para se realizar todas as estimações deste artigo.

13 Salientam-se as limitações das estimativas realizadas, visto que não se incluem variáveis de controle nas regressões. Optou-se por seguir a literatura padrão sobre o assunto ao se fazer as estimativas. Na Tabela 3, são feitas estimações com dummies regionais em que diferenças entre as macrorregiões do Estado de Minas Gerais são permitidas. Além disso, as elasticidades variam regionalmente. Dessa forma, tentou-se, ao menos em parte, minimizar as deficiências das equações 2 e 3.

\section{1_Elasticidade "pobreza-crescimento"}

Inicialmente, seguindo a primeira definição, busca-se mensurar a elasticidade da pobreza em relação ao crescimento da renda per capita para os municípios do Estado de Minas Gerais. Por elasticidade, entende-se o quanto a variável dependente varia em relação a uma alteração na variável explicativa. Dessa forma, a elasticidade "pobreza-crescimento" mede a variação percentual da proporção de pobres (ou indigentes) devido a uma variação percentual na taxa de crescimento da renda per capita. Seguindo a sugestão de Ravallion (2001) e Ravallion e Datt (1999), considera-se, de forma bastante simples, a associação entre crescimento da renda per capita e redução da pobreza. Formalmente, como exposto em Silveira Neto (2005), considere-se, pois, a renda per capita y, uma linha de pobreza $y_{p}$ e a função de distribuição acumulada da renda per capita $F(y)$. Obtendo, assim, a proporção de pobres como $P=F\left(y_{p}\right)$ e a renda domiciliar per capita média $\mu=E(y)$, é possível expressar uma relação entre proporção de pobre e renda per capita média na forma:

$\ln F\left(y_{p}\right)=\alpha+\beta \ln \mu+\varepsilon$

em que $\varepsilon$ corresponde a um termo de erro. Observe que o coeficiente $\beta$ nessa relação pode ser interpretado como uma elasticidade "pobreza-crescimento", já que apreende a variação percentual da proporção de pobres em função de uma variação percentual da renda per capita média. O modelo estimado é o resultado da diferença entre a equação (1) para os dois pontos no tempo (1991 e 2000, no caso deste trabalho). Utiliza-se o método de mínimos quadrados ordinários (MQO) ${ }^{12}$ para a estimação dos modelos e dados dos 853 municípios de Minas Gerais.

Evidentemente, dada a simplicidade, a relação entre crescimento econômico e pobreza está muito longe de explicar os meios pelos quais o crescimento econômico afeta as condições de pobreza, mas, dado o caráter exploratório da investigação, evidências empíricas a respeito da relação são consideradas a seguir. ${ }^{13}$ Obtêm-se evidências a respeito da relação entre crescimento econômico e redução da pobreza no Estado de Minas Gerais e a respeito de potenciais diferenciações para as macrorregiões com respeito a essa relação no período 1991-2000.

Assume-se primeiramente um modelo bastante restrito, visto que não permite diferenças regionais, dentro do Estado de Minas Gerais, quanto à elasticidade "pobreza-crescimento", nem em relação ao intercepto. Os resultados para as duas linhas de pobreza (indigentes e pobres, respectivamente) são apresentados a seguir: 


$$
\begin{aligned}
\ln [\Delta \text { indigentes }]= & -0,08-1,17 \ln [\Delta y](2) \\
& (0,029)^{*}(0,072)^{*}
\end{aligned}
$$

em que $\left(^{*}\right.$ ) é o desvio padrão entre parênteses e robustos à heterocedasticidade.

$F=324,70 ; \quad R^{2}=0,28$; número de observações $=853$.

Obs: $\ln [\Delta$ indigentes $]=$ taxa de variação da proporção de indigentes entre 1991-2000; $\ln [\Delta y]=$ taxa de variação da renda per capita entre 1991-2000.

$$
\begin{aligned}
\ln [\Delta \text { pobres }]=- & -0,11-0,66 \ln [\Delta y] \\
& (0,016)^{*}(0,040)^{*}
\end{aligned}
$$

em que $\left(^{*}\right)$ é o desvio padrão entre parênteses e robustos à heterocedasticidade.

$F=302,55 ; \quad R^{2}=0,26 ; \quad$ número de observações $=853$.

Obs: $\ln [\Delta$ pobres $]=$ taxa de variação da proporção de pobres entre 1991-2000; $\ln [\Delta y]=$ taxa de variação da renda per capita entre 1991-2000.

O resultado da equação 2 , em que é adotada a linha de indigência, ${ }^{14}$ mostra que no período 1991-2000 um crescimento da renda per capita de $1 \%$ esteve associado a uma redução $1,17 \%$ no percentual de indigentes. Quando se utiliza uma linha de pobreza mais elevada $^{15}$ (equação 3), é verificada uma redução do coeficiente, isto é, um crescimento da renda per capita de $1 \%$ se relaciona a uma redução $0,66 \%$ no percentual de pobres. ${ }^{16}$
A seguir, são feitas estimações permitindo que tanto o intercepto quanto as elasticidades possam variar regionalmente, ou seja, diferenças entre as dez macrorregiões do Estado de Minas Gerais são permitidas. Assim, dadas as diferenças regionais que podem afetar o impacto sobre a redução da pobreza, como, por exemplo, níveis de escolaridade, saúde e desigualdade de renda, foram feitas as estimações (I) e (II) apresentadas na Tabela 3.

Primeiramente, em relação à coluna (I), verifica-se que o crescimento da renda per capita dos municípios da macrorregião do Triângulo Mineiro não teve impacto sobre a variação do percentual de indigentes no período 1991-2000. Já as evidências para os municípios das outras nove macrorregiões sugerem uma elasticidade "pobreza-crescimento" negativa e significativa. Por exemplo, a macrorregião do Sul de Minas apresentou a maior elasticidade, ou seja, um crescimento da renda per capita de $1 \%$ esteve relacionado com uma redução de $1,79 \%$ no percentual de indigentes. Já a macrorregião da Zona da Mata foi a que obteve a menor elasticidade, em outras palavras, um crescimento da renda per capita de $1 \%$ esteve associado a uma redução de apenas $0,4 \%$ no percentual de indigentes.
4 Percentual de pess renda domiciliar per capita abaixo de $\mathrm{R} \$ 37,75$ (equivalente a $1 \frac{4}{4}$ salário mínimo de agosto de 2000).

15 Percentual de pessoas com renda domiciliar per capita abaixo de $\mathrm{R} \$ 75,50$ (equivalente a $1 / 2$ salário mínimo de agosto de 2000).

16 Tais valores são próximos daqueles obtidos por Silveira Neto (2005), para o mesmo período, para a região Sudeste do Brasil como um todo, que foram de $-1,60$ e $-0,85 \%$ para a equação 2 e 3 , respectivamente. 
Tabela 3_Relação entre crescimento econômico e redução da pobreza nas macrorregiões de Minas Gerais

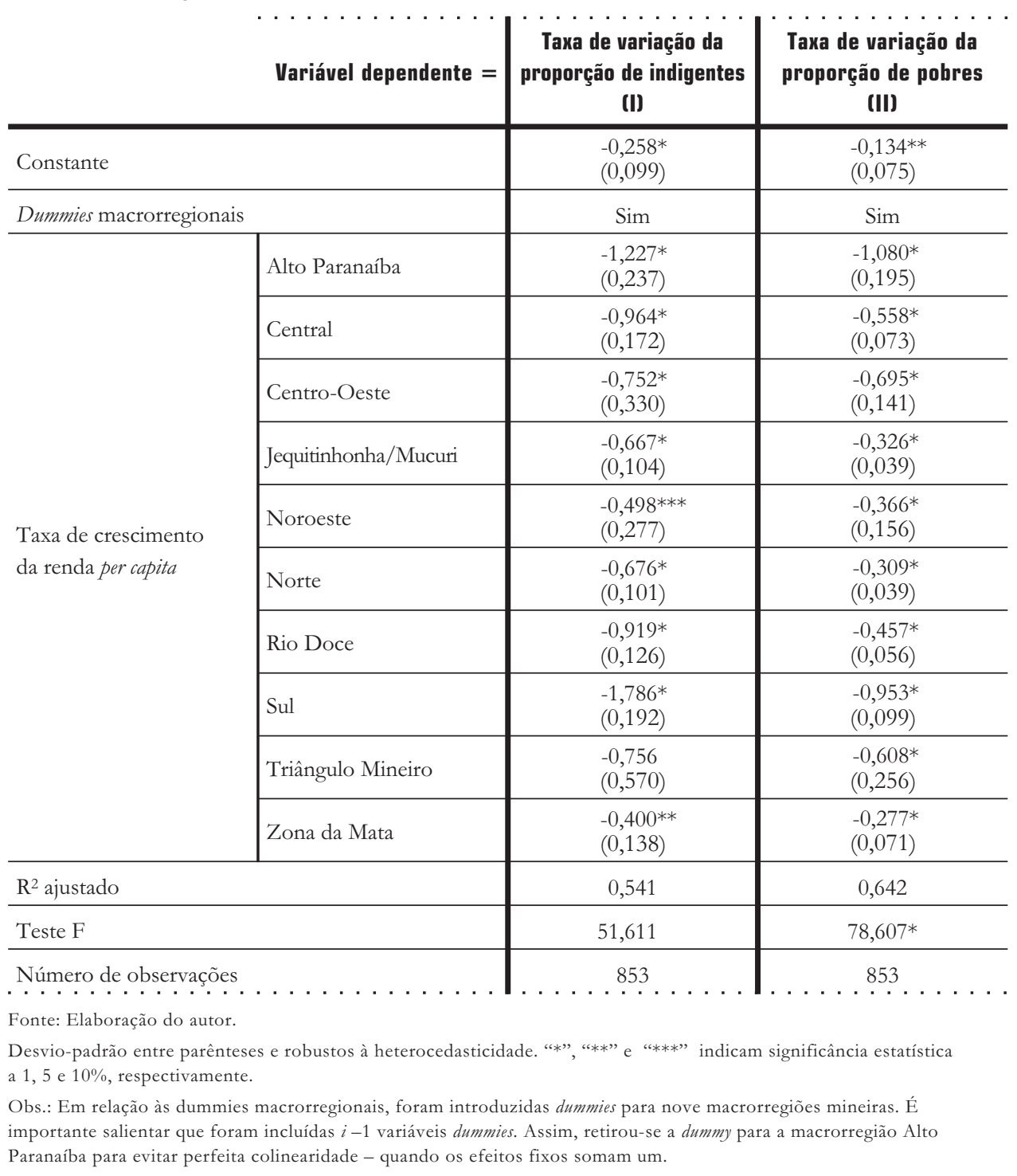


Na coluna (II) estima-se a relação entre crescimento da renda per capita e uma variação no percentual de pobres. Nessa estimação todas as macrorregiões apresentaram coeficientes significantes estatisticamente e negativos. As macrorregiões do Alto-Paranaíba e do Sul de Minas apresentaram as maiores elasticidades "pobrezacrescimento", cerca de $-1,08 \%$ e $-0,95 \%$, respectivamente. Isso significa que um crescimento da renda per capita de 1\% nos municípios dessas regiões esteve associado a reduções de $1,08 \%$ e $0,95 \%$ no percentual de pobres dos municípios do Alto-Paranaíba e do Sul de Minas, respectivamente.

Comparando as estimações (I) e (II), verifica-se maior elasticidade "pobreza-crescimento" quando se usa a variação no percentual de indigentes. Isso acontece devido ao fato de que, quanto mais baixa a linha de pobreza utilizada, maior é a possibilidade de pequenos ganhos de renda repercutir na redução da pobreza. Assim, para uma mesma taxa de crescimento da renda per capita, tem-se maior redução da indigência do que da pobreza, visto que o ganho de renda dos indigentes precisa ser menor para que esses ultrapassem a linha de pobreza (renda) considerada.

A título de ilustração, pode-se perceber a grande diferença na magnitude entre os coeficientes das macrorregiões do Sul de Minas e da Zona da Mata. Isso tanto pode ser explicado pela maior intensidade da pobreza dos pobres na Zona da Mata (maior distância desses pobres da linha de pobreza), por exemplo, como pelo menor crescimento relativo da renda dos mais pobres. Com essa última noção em mente, faz sentido considerar a segunda definição de crescimento pró-pobre proposto por Son (2004). Antes, porém, explora-se a sugestão de Ravallion (1997), em que se verifica a importância que a desigualdade de renda tem no impacto do crescimento econômico sobre a pobreza. ${ }^{17}$

$\begin{array}{ll}17 \text { Existem dois argumentos } & \text { segundo link, do crescimento } \\ \text { para explicar o porquê da } & \text { para a redução da pobreza ver } \\ \text { importância da distribuição de } & \text { Lipton e Ravallion (1995) e } \\ \text { renda inicial para a } & \text { Bruno et al. (1995). Existe um } \\ \text { subseqüente redução da taxa } & \text { segundo argumento ligando } \\ \text { de pobreza. O primeiro } & \text { distribuição de renda inicial à } \\ \text { argumento é que uma maior } & \text { redução da taxa de pobreza. } \\ \text { desigualdade pode acarretar em } & \text { Assume-se um processo de } \\ \text { uma menor taxa de } & \text { crescimento no qual todos os } \\ \text { crescimento da renda per capita } & \text { níveis de renda crescem à } \\ \text { média subseqüente, e assim } & \text { mesma taxa. Então, uma maior } \\ \text { uma menor taxa de redução da } & \text { desigualdade acarretará que os } \\ \text { pobreza absoluta. Existem dois } & \text { pobres ganharão menos do } \\ \text { links nesse argumento: um da } & \text { crescimento em termos } \\ \text { distribuição de renda inicial } & \text { absolutos; os pobres terão } \\ \text { para o crescimento, e outro do } & \text { menor parte tanto da renda } \\ \text { crescimento para a redução da } & \text { total quanto de seu incremento } \\ \text { pobreza. Para o primeiro link, } & \text { através do crescimento; logo, a } \\ \text { ver Persson e Tabellini (1994), } & \text { taxa de redução da pobreza } \\ \text { Alesina e Rodrick (1994) e } & \text { deve ser menor. Neste artigo } \\ \text { Benabou (1996). Argumentos e } & \text { obtém-se evidências a respeito } \\ \text { evidências em relação ao } & \text { deste último argumento. }\end{array}$


$18 \ldots \ldots \ldots \ldots$

18 O município de Delta (no Triângulo Mineiro) tem o índice de Gini de 0,41, que é o menor valor verificado em 1991 para os municípios mineiros. Já o município de Manga (no Norte de Minas) apresenta um índice de Gini de 0,73, que é o maior entre os municípios mineiros em 1991.

\section{2_ Taxa de crescimento "corrigida pela desigualdade"}

A hipótese a ser testada nesta subseção é que à medida que a desigualdade aumenta, a taxa de redução da pobreza torna-se menos sensível ao crescimento da renda per capita média, e chega a zero quando a desigualdade é suficientemente alta (Ravallion, 1997). Assumindo que a elasticidade da redução da pobreza em relação ao crescimento cai linearmente quando a desigualdade aumenta, e chega a zero quando a pessoa mais rica possui toda a renda, a taxa de redução da pobreza pode ser estimada a partir da seguinte relação:

$r=\alpha+\beta(1-$ gini $) \Delta y+\varepsilon$

em que $r$ corresponde à variação percentual da proporção de pobres entre $1991 \mathrm{e}$ 2000, Gini é uma medida da desigualdade de renda no início do período (neste caso o índice de Gini em 1991) e $\Delta y$ a taxa de crescimento da renda per capita média entre 1991 e 2000. Assim, a taxa de redução da pobreza é diretamente proporcional à taxa de crescimento "corrigida pela desigualdade" ("distribution-corrected" growth rate), $(1-$ gini $) \Delta y$.

A partir do universo dos 853 municípios mineiros e utilizando as duas linhas de pobreza (indigentes e pobres, respectivamente), tem-se os seguintes resultados:

$$
\begin{gathered}
r=-0,16-2,07(1-\text { gini }) \cdot \Delta y \\
(0,030)^{*}(0,154)^{*}
\end{gathered}
$$

em que (*) é o desvio padrão entre parênteses e robustos à heterocedasticidade. $F=227,58 ; \quad R^{2}=0,21 ; \quad$ número de observações $=853$.

$$
\begin{gathered}
r=-0,15-1,22(1-\text { gin }) \cdot \Delta y \\
(0,016)^{*}(0,085)^{*}
\end{gathered}
$$

em que (*) é o desvio padrão entre parênteses e robustos à heterocedasticidade. $F=234,79 ; R^{2}=0,21$; número de observações $=853$.

Os resultados apresentados nas equações 5 e 6 sugerem um importante condicionante da desigualdade de renda sobre a relação entre crescimento e redução da pobreza. Especificamente, os valores indicam que 1\% de crescimento da renda per capita no período 1991-2000 estaria associado a reduções na proporção de indigentes de 1,22 e $0,56 \%$ para os municípios com índices de Gini, respectivamente, com valores 0,41 e $0,73 .^{18}$ Quando se analisa a redução na proporção de pobres, os valores indicam que $1 \%$ de crescimento da renda per capita no período 1991-2000 estaria associado a reduções na proporção de pobres de 0,72 e $0,33 \%$ para os municípios com índices de Gini, respectivamente, com valores 0,41 e 0,73. Em outras palavras, quanto menor a desigualdade de renda, maior é o impacto do crescimento econômico sobre a redução da pobreza. 
Até esse ponto, a análise do crescimento econômico do Estado de Minas Gerais teve como base a primeira definição que considera crescimento pró-pobre aquele crescimento que reduz a pobreza. Os resultados obtidos apontam uma relativa menor elasticidade "pobreza-crescimento" para algumas macrorregiões, que pode tanto estar associado à maior intensidade da pobreza dos pobres em determinada macrorregião, como ao fato de que a renda dos mais pobres ter crescido relativamente menos rapidamente que a renda per capita média na macrorregião. A partir de agora, é investigada essa possibilidade.

\section{3_ Curva crescimento pobreza de Son}

Esta subseção tem como foco a segunda definição de crescimento pró-pobre. Analisa-se, assim, o crescimento econômico do ponto de vista qualitativo ("qualidade" do crescimento da renda per capita); em outras palavras, verifica-se quanto os pobres se beneficiaram em relação ao crescimento da renda per capita. Com essa análise será possível observar em que medida o crescimento econômico das macrorregiões e dos municípios de Minas Gerais tem se revelado um mecanismo relativamente eficaz de combate à pobreza do Estado. Uma maneira de se estudar essa questão é analisar o cresci- mento da renda domiciliar per capita dos mais pobres em relação ao crescimento da renda média de toda a população. Caso o crescimento da renda per capita dos pobres for maior que o da renda per capita média, tem-se um crescimento econômico pró-pobre, ou seja, um tipo de crescimento que está associado à diminuição da desigualdade (Kakwani e Pernia, 2000; Son, 2004). Assim, para o período 1991 2000, uma das questões respondidas por este trabalho foi: o crescimento econômico dos municípios de Minas Gerais tem sido pró-pobre? Para responder a essa pergunta, traçou-se a "curva crescimento pobreza de Son" para cada um dos 853 municípios (e para cada macrorregião) de Minas Gerais. Essa curva nos mostra como o crescimento da renda per capita dos mais pobres tem se comportado em relação ao crescimento da renda média per capita.

Como bem salienta Son (2004), sabe-se que a performance de crescimento econômico difere-se entre regiões. Algumas regiões têm experimentado uma taxa de crescimento maior que outras. Do mesmo modo, as evidências mostram que, entre regiões, pode existir uma grande variação na redução da pobreza dada uma mesma taxa de crescimento econômico. Isso sugere que o crescimento em algumas re- 
Esa

19 Essa metodologia

foi integralmente extraída

de Son (2004).

20 A curva de Lorenz satisfaz as seguintes propriedades

(Kakwani, 1980):

(i) $L(p)=0$ quando $p=0$;

(ii) $L(p)=100$ quando $p=100$;

(iii) $\mathrm{d} L(p) / d p=y / \mu>0$

e $d^{2} L(p) / d p^{2}=1 / \mu f(y)>0$;

(iv) $L(p) \leq p$ para todo o

intervalo $0<p<100$.

Quando $L(p)=p$,

tem-se uma perfeita

distribuição de renda. giões é mais pró-pobre do que em outras. Adota-se, assim, a metodologia proposta recentemente por Son (2004), que vincula os diferentes possíveis impactos do crescimento econômico sobre os pobres a diferentes comportamentos da curva de Lorenz, necessária para a determinação do bastante conhecido índice de desigualdade de Gini.

Suponha que $L(p)$ é a curva de Lorenz, que descreve a participação na renda dos indivíduos situados entre os $p \%$ que pode ser definida como: ${ }^{19}$

$L(p)=\frac{1}{\mu} \int_{0}^{x} y f(y) d y$

em que:

$p=\int_{0}^{x} f(y) d y$

$y$ é a renda domiciliar per capita com sua função densidade sendo $f(y)$ e $\mu$ é a renda média dessa distribuição. ${ }^{20}$

Seguindo Kakwani e Pernia (2000), o crescimento econômico pode ser chamado de pró-pobre se os pobres se beneficiam do crescimento proporcionalmente mais do que os não-pobres. Nesse cenário, a desigualdade de renda é simultaneamente declinante durante o processo de crescimento. Uma mudança na curva de Lorenz indica se a desigualdade é crescente ou decrescente com o crescimento econômico. Assim, o crescimento é claramente pró-pobre se to- da a curva de Lorenz se desloca para cima, $\Delta L(p) \geq 0$ para todo $p$.

Baseando-se no teorema de Atkinson (1987), que permite associar deslocamentos para cima da Curva de Lorenz (elevações de $L(p)$ para todo $p$ ) a diminuições de pobreza, Son (2004) propõe a elaboração de uma "curva de crescimento-pobreza" que permite determinar a "qualidade" do crescimento (pró-pobre, não pró-pobre ou "empobrecedor") a partir da avaliação do crescimento da renda de cada $p$ por cento mais pobres da população, onde $p=0, \ldots, 100$.

Segundo Son (2004) quando toda a curva de Lorenz se desloca para cima (baixo), pode-se afirmar, sem ambigüidade, que a pobreza diminuiu (aumentou). Esse resultado é válido para toda a classe de medidas de pobreza e todas as linhas de pobreza. Essa conclusão servirá de base para a "curva crescimento-pobreza".

Da definição da curva de Lorenz, pode-se escrever:

$L(p)=\frac{\mu_{p} p}{\mu}$

que expressa a participação na renda dos $p \%$ mais pobres, onde $\mu_{p}$ é a média da renda dos indivíduos $p \%$ mais pobres da população. Operando-se com os logaritmos de ambos os lados, a equação (9) torna-se: 
$L n(\mu p)=\operatorname{Ln}(\mu L(p))-L n(p)$

A partir da diferença entre dois pontos no tempo da equação (10), tem-se:

$g(p)=\Delta \operatorname{Ln}(\mu L(p))$

em que:

$g(p)=\Delta \operatorname{Ln}\left(\mu_{p}\right)$

é a taxa de crescimento da renda média dos $p \%$ mais pobres da população quando os indivíduos são ordenados em ordem crescente de renda per capita. $g(p)$ varia com $p$ indo de 0 a 100 e pode ser chamado de curva de crescimento-pobreza. É importante notar que $g(p)$ não mede o crescimento da renda média do decil $p$, mas o crescimento da renda média até $\mathrm{O}$ decil $p .{ }^{21}$ Com base no teorema de Atkinson e da equação (11), pode-se afirmar que se $g(p)>0[g(p)<0]$ para todo $p$, então a pobreza diminuiu (aumentou), sem ambigüidade, entre dois períodos.

A equação (11) pode também ser escrita como:

$g(p)=g+\Delta \operatorname{Ln}(L(p))$

e

$g=\Delta \operatorname{Ln}(\mu)$

em que $g$ é a taxa de crescimento da renda média per capita de toda a sociedade.
Observe que quando $p=100, g(p)=g$ visto que $\Delta L(p)=0$ em $p=100$.

Baseando-se na equação (13), segue que:

1. se $g(p)>g$ para todo $p<100$, então o crescimento é pró-pobre visto que toda a curva de Lorenz desloca-se para cima $(L(p)>0$ para todo $p)$;

2. se $0<g(p)<g$ para todo $p<100$, então o crescimento reduz a pobreza, mas é acompanhado por um aumento da desigualdade $[L(p)<0$ para todo $p]$. Em outras palavras, o crescimento reduz a pobreza, mas os pobres recebem proporcionalmente menos benefícios do que os não-pobres, situação essa em que o crescimento seria não pró-pobre.

3. se $g(p)<0$ para todo $p<100$ e $g>0$, então, tem-se um crescimento "empobrecedor", em que um crescimento econômico positivo aumenta a pobreza.

4. demais casos: inconclusivo.

A curva de crescimento-pobreza pode ser estimada com base nos dados de renda média por decil (ou quintil) de renda para quaisquer dois períodos. Assim, basta calcular a taxa de variação

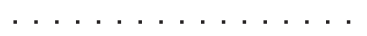
21 Por exemplo, a renda média até o segundo decil é a média das rendas do primeiro e segundo decis. Seguindo o raciocínio, a renda média até o décimo decil é a renda média da população. 
da renda até cada decil entre dois períodos bases e plotar contra os decis de renda, como é feito para a curva de Lorenz. Nesse caso, a taxa de variação do último decil equivale à taxa de crescimento da renda média no período. Se a linha tem inclinação negativa isso significa que os decis de renda menores cresceram acima da renda média e, conseqüentemente, a renda dos mais pobres cresceu a taxas maiores do que a dos ricos ou do que os decis de renda mais elevados. Isso significa que a pobreza tem diminuído no período analisado.

$\mathrm{Na}$ Tabela 4, são apresentados os resultados para as dez macrorregiões e para o Estado de Minas Gerais como um todo. Em seguida, os resultados são traçados nos Gráficos 2 e 3. Evidências em relação à "qualidade" do crescimento econômico para os 853 municípios mineiros também são mostradas.

Tabela 4_Crescimento anual da renda "per capita" dos p\% mais pobres (em \%) e classificação das macrorregióes do Estado de Minas Gerais de acordo com a "qualidade" do crescimento econômico - 1991-2000

\begin{tabular}{|c|c|c|c|c|c|c|}
\hline \multirow{2}{*}{ Macrorregião } & \multicolumn{5}{|c|}{ Taxa de crescimento da renda "per capita" dos p\% mais pobres (ao ano) } & \multirow{2}{*}{$\begin{array}{l}\text { "Qualidade" } \\
\text { de crescimento }\end{array}$} \\
\hline & $20 \%$ & $40 \%$ & $60 \%$ & $80 \%$ & $100 \%$ & \\
\hline Alto Paranaíba & 4,36 & 4,62 & 4,50 & 4,19 & 4,39 & Inconclusivo \\
\hline Central & 1,76 & 2,62 & 2,86 & 2,95 & 3,10 & Não pró-pobre \\
\hline Centro-Oeste de Minas & 5,22 & 5,41 & 5,31 & 5,09 & 5,13 & Inconclusivo \\
\hline Jequitinhonha/Mucuri & $-1,98$ & 1,31 & 2,39 & 3,11 & 3,78 & Inconclusivo \\
\hline Noroeste de Minas & 1,27 & 3,30 & 3,80 & 4,03 & 5,93 & Não pró-pobre \\
\hline Norte de Minas & $-2,47$ & 0,82 & 2,17 & 3,01 & 3,63 & Inconclusivo \\
\hline Rio Doce & 1,76 & 3,46 & 4,10 & 4,46 & 4,73 & Não pró-pobre \\
\hline Sul de Minas & 4,03 & 4,36 & 4,36 & 4,33 & 4,43 & Não pró-pobre \\
\hline Triângulo Mineiro & 1,67 & 2,42 & 2,61 & 2,72 & 3,50 & Não pró-pobre \\
\hline Zona da Mata & 4,06 & 4,67 & 4,75 & 4,75 & 4,60 & Inconclusivo \\
\hline Estado de Minas Gerais & 2,59 & 3,43 & 3,66 & 3,73 & 3,95 & Não pró-pobre \\
\hline
\end{tabular}

Fonte: Elaboração própria com base em dados dos Censos Demográficos de 1991 e 2000. 
Gráfico 2_ Taxa de crescimento anual da renda "per capita" por quintis de pobres (1991-2000) - macrorregiões que apresentaram crescimento não pró-pobre

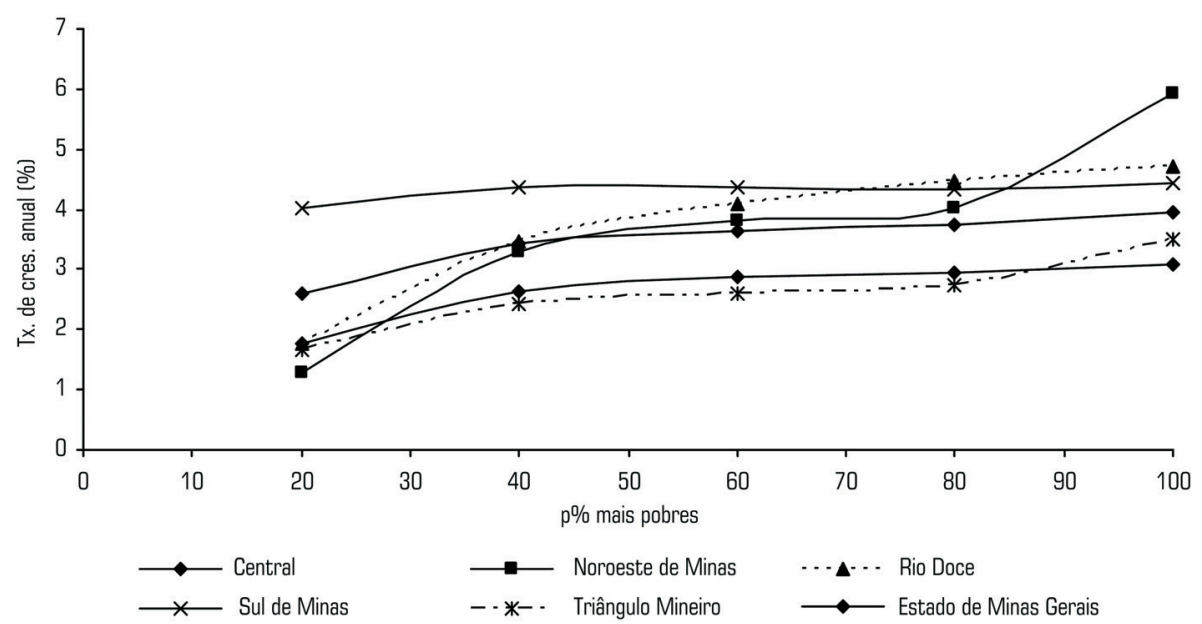

Fonte: Elaboração própria com base em dados dos Censos Demográficos de 1991 e 2000.

Gráfico 3_ Taxa de crescimento anual da renda "per capita" por quintis de pobres (1991-2000) - macrorregióes que apresentaram crescimento inconclusivo

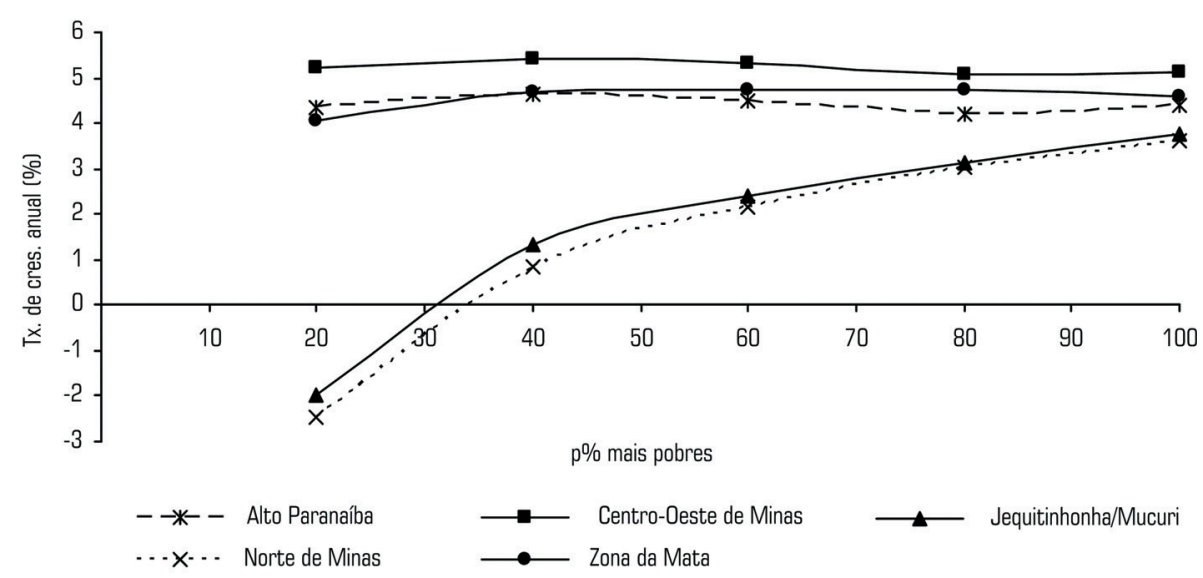

Fonte: Elaboração própria com base em dados dos Censos Demográficos de 1991 e 2000. 
De início, de acordo com a Tabela 4, é possível observar que nenhuma macrorregião apresentou crescimento pró-pobre pela definição de Son (2004). Em outras palavras, nenhuma região apresentou taxa de crescimento da renda per capita média de todos os $p \%$ mais pobres, $\operatorname{com} p<100$, maior que aquela verificada para a renda per capita média de toda a população $(\mathrm{p}=100)$. O Gráfico 2 apresenta as curvas "crescimento-pobreza" para as cinco macrorregiões e para o Estado de Minas Gerais onde o crescimento econômico é considerado não pró-pobre. Pode-se anotar, assim, que as macrorregiões Central, Noroeste de Minas, Rio Doce, Sul de Minas e Triângulo Mineiro apresentaram um crescimento não pró-pobre: a taxa de crescimento de todos os quintis foi positiva, e a taxa de crescimento da renda dos $p \%$ mais pobres, $p<100$, foi sempre menor que aquela de toda a população. A Tabela 4 explicita os valores observados no Gráfico 2. Por exemplo, em relação ao Estado de Minas Gerais, a taxa de crescimento anual da renda per capita dos 20, 40, 60 e $80 \%$ mais pobres foi de $2,59,3,43,3,66$ e $3,73 \%$, respectivamente, sempre abaixo da taxa de crescimento da renda per capita de toda a população, que foi de 3,95\%. Conclui-se, portanto, que os mais pobres se beneficiaram relativamente menos em relação ao crescimento econômico.
Já as outras cinco macrorregiões, Alto Paranaíba, Centro-Oeste de Minas, Jequitinhonha/Mucuri, Norte de Minas e Zona da Mata, apresentaram resultados inconclusivos, que podem ser evidenciados no Gráfico 3.

Como já observado na seção 2 , a evolução da pobreza apresenta variações dentro das macrorregiões. Da mesma forma, a "qualidade" do crescimento econômico pode variar dentro dessas. No intuito de evidenciar essas diferenças, a Tabela 5 apresenta os resultados quanto à "qualidade" do crescimento da renda per capita para os 853 municípios do Estado de Minas Gerais.

No Gráfico 2 quando foi traçada a curva "crescimento-pobreza" para o Estado de Minas Gerais como um todo, encontrouse um padrão de crescimento não pró-pobre. Entretanto, quando se traça essa curva para cada um dos 853 municípios, o resultado permite apreender variações dentro do Estado e das macrorregiões. Primeiramente, de acordo com a Tabela 5 , pode-se perceber que 202 municípios apresentaram crescimento pró-pobre, ou cerca de $23,7 \%$ dos municípios do Estado. O crescimento não pró-pobre esteve presente em 216 municípios (25,3\% do total), em 35 municípios o crescimento foi "empobrecedor" ( $4,1 \%$ do total) e em 400 municípios o crescimento foi inclusivo $(46,9 \%$ do total). 
Tabela 5_Distribuição dos municípios do Estado de Minas Gerais de acordo com a "qualidade" do crescimento econômico - 1991-2000

\begin{tabular}{|c|c|c|c|c|c|c|c|c|c|c|}
\hline \multirow{2}{*}{$\begin{array}{l}\text { Macrorregião } \\
\text { Alto Paranaíba }\end{array}$} & \multicolumn{2}{|c|}{$\begin{array}{l}\text { Crescimento } \\
\text { Pró-Pobre }\end{array}$} & \multicolumn{2}{|c|}{$\begin{array}{l}\text { Crescimento } \\
\text { Não Pró-Pobre }\end{array}$} & \multicolumn{2}{|c|}{$\begin{array}{l}\text { Crescimento } \\
\text { Empobrecedor }\end{array}$} & \multicolumn{2}{|c|}{ Inconclusivo } & \multicolumn{2}{|c|}{$\begin{array}{c}\text { Número } \\
\text { de Municípios }\end{array}$} \\
\hline & 15 & $(48,4 \%)$ & 9 & $(29,0 \%)$ & 1 & $(3,2 \%)$ & 6 & $(19,4 \%)$ & 31 & $(100 \%)$ \\
\hline Central & 32 & $(20,3 \%)$ & 42 & $(26,6 \%)$ & 4 & $(2,5 \%)$ & 80 & $(50,6 \%)$ & 158 & $(100 \%)$ \\
\hline Centro-Oeste de Minas & 27 & $(48,2 \%)$ & 16 & $(28,6 \%)$ & 0 & $(0,0 \%)$ & 13 & $(23,2 \%)$ & 56 & $(100 \%)$ \\
\hline Jequitinhonha/Mucuri & 3 & $(4,5 \%)$ & 10 & $(15,2 \%)$ & 5 & $(7,6 \%)$ & 48 & $(72,7 \%)$ & 66 & $(100 \%)$ \\
\hline Noroeste de Minas & 1 & $(5,3 \%)$ & 9 & $(47,4 \%)$ & 0 & $(0,0 \%)$ & 9 & $(47,4 \%)$ & 19 & $(100 \%)$ \\
\hline Norte de Minas & 1 & $(1,1 \%)$ & 3 & $(3,4 \%)$ & 20 & $(22,5 \%)$ & 65 & $(73,0 \%)$ & 89 & $(100 \%)$ \\
\hline Rio Doce & 12 & $(11,8 \%)$ & 24 & $(23,5 \%)$ & 2 & $(2,0 \%)$ & 64 & $(62,7 \%)$ & 102 & $(100 \%)$ \\
\hline Sul de Minas & 61 & $(39,4 \%)$ & 49 & $(31,6 \%)$ & 3 & $(1,9 \%)$ & 42 & $(27,1 \%)$ & 155 & $(100 \%)$ \\
\hline Triângulo Mineiro & 5 & $(14,3 \%)$ & 14 & $(40,0 \%)$ & 0 & $(0,0 \%)$ & 16 & $(45,7 \%)$ & 35 & $(100 \%)$ \\
\hline Zona da Mata & 45 & $(31,7 \%)$ & 40 & $(28,2 \%)$ & 0 & $(0,0 \%)$ & 57 & $(40,1 \%)$ & 142 & $(100 \%)$ \\
\hline Estado de Minas Gerais & 202 & $(23,7 \%)$ & 216 & $(25,3 \%)$ & 35 & $(4,1 \%)$ & 400 & $(46,9 \%)$ & 853 & $(100 \%)$ \\
\hline
\end{tabular}

Fonte: Elaboração própria com base em dados dos Censos Demográficos de 1991 e 2000.

Também, diferenças entre macrorregiões podem ser evidenciadas. Enquanto que, de acordo com a Tabela 5, cerca de $48 \%$ dos municípios das regiões do Alto $\mathrm{Pa}$ ranaiba e Centro-Oeste de Minas apresentaram crescimento pró-pobre, a região do Norte de Minas apresentou apenas um município com esse padrão de crescimento da renda per capita, ou seja, 1,1\% do total da macrorregião. Já em relação ao crescimento não pró-pobre, a região Noroeste de Minas apresentou o maior percentual, 47,4\%, enquanto o Norte de Minas obteve o menor, $3,4 \%$. Vale ressaltar que o Norte de Minas é a região com um dos piores padrões de crescimento econômico. Essa região obteve o maior percentual de crescimento econômico empobrecedor, $22,5 \%$, em que um crescimento econômico positivo aumentou a pobreza desses municípios.

O Mapa 4 do Anexo mostra a distribuição espacial dos municípios mineiros de acordo com a "qualidade" do crescimento econômico. Por exemplo, evidencia a concentração de municípios com padrão de crescimento pró-pobre nas regiões do Alto Paranaíba e Centro-Oeste de Minas. Já em relação ao crescimento não pró-pobre, a concentração de municípios está nas regiões Noroeste de Minas e Triângulo Mineiro. 
22 Por exemplo, levando conceitos em consideração, a macrorregião do Centro-Oeste de Minas antes considerada como tendo um resultado inconclusivo, poderia ser enquadrada em uma situação de crescimento pró-pobre fraca (ver Tabela 4).
Entretanto, dado o grande número de casos inconclusivos, que somam 400 municípios (ou 47\% do total), pode-se estar fornecendo um cenário impreciso da dinâmica da renda dos mais pobres $(40 \%$ mais pobres, por exemplo). Nesse sentido, é interessante usar um conceito menos estrito de crescimento pró-pobre. É importante destacar que no Norte de Minas os casos inconclusivos chegam a 73\% do total de municípios da região.

Como bem destaca Silveira Neto (2005), esses resultados inconclusivos incluem duas situações distintas. A primeira, ocasiões em que o crescimento da renda dos $p \%$ mais pobres, $\operatorname{com} p=1, \ldots, 40$, é maior que aquele verificado para renda média de toda a população (onde $p=100$ ), mas para ao menos para algum $p$ intervalo $40<p<100$ o crescimento da renda média é menor que aquele observado para renda média de toda a população. A segunda, situações em que o crescimento da renda de pelo menos algum dos $p \%$ mais pobres, $\operatorname{com} p=1, \ldots, 40$, é menor que aquele verificado para renda média para $p=100$, mas para $p$ intervalo $40<p<100$ o crescimento da renda média é maior que aquele observado para renda média de toda a população. Tais distintas situações poderiam assumir as denotações, respectivamente, de situação "pró-pobre fraca", 22 situação "não pró-pobre fraca".
Uma terceira possibilidade verificada neste trabalho mostra um crescimento negativo da renda dos $\not \%$ mais pobres, $\operatorname{com} p=1, \ldots, 40$, mas um crescimento positivo da renda média da população. Caso esse que se poderia denotar de crescimento "empobrecedor fraco". Visto que um crescimento positivo da renda per capita média aumenta a pobreza de pelo menos uma parcela da população (os $40 \%$ mais pobres). Esse é o caso da maioria absoluta dos municípios do Jequitinhonha/Mucuri e do Norte de Minas apresentados na Tabela 6 , e que também podem ser evidenciados no Mapa 5 do Anexo.

Como pode ser percebido de acordo com a análise do Mapa 5 do Anexo, a seguir, em comparação com o Mapa 4 do Anexo, há um significativo número de municípios (183 municípios) que antes apresentava um resultado inconclusivo e que agora pode receber uma classificação mais informativa.

De fato, o percentual de municípios com classificação inconclusiva passa de $46,9 \%$ do total para $25,4 \%$. Por sua vez, o percentual de municípios com um crescimento empobrecedor passa de 4,1 para $14,9 \%$, o percentual de municípios com um crescimento não pró-pobre passa de 25,3 para $33,1 \%$ e aqueles que apresentam um crescimento pró-pobre sobe de 23,7 para $26,6 \%$. 
Tabela 6_ Distribuição dos municípios do Estado de Minas Gerais de acordo com a "qualidade" do crescimento econômico - 1991-2000 (conceito menos estrito)

\begin{tabular}{|c|c|c|c|c|c|c|c|c|c|c|}
\hline Macrorregião & \multicolumn{2}{|c|}{$\begin{array}{l}\text { Crescimento } \\
\text { Pró-Pobre }\end{array}$} & \multicolumn{2}{|c|}{$\begin{array}{l}\text { Crescimento } \\
\text { Não Pró-Pobre }\end{array}$} & \multicolumn{2}{|c|}{$\begin{array}{l}\text { Crescimento } \\
\text { Empobrecedor }\end{array}$} & \multicolumn{2}{|c|}{ Inconclusivo } & \multicolumn{2}{|c|}{$\begin{array}{c}\text { Número } \\
\text { de Municípios }\end{array}$} \\
\hline Alto Paranaíba & 17 & $(54,8 \%)$ & 9 & $(29,0 \%)$ & 1 & $(3,2 \%)$ & 4 & $(12,9 \%)$ & 31 & $(100 \%)$ \\
\hline Central & 38 & $(24,1 \%)$ & 57 & $(36,1 \%)$ & 17 & $(10,8 \%)$ & 46 & $(29,1 \%)$ & 158 & $(100 \%)$ \\
\hline Centro-Oeste de Minas & 29 & $(51,8 \%)$ & 20 & $(35,7 \%)$ & 1 & $(1,8 \%)$ & 6 & $(10,7 \%)$ & 56 & $(100 \%)$ \\
\hline Jequitinhonha/Mucuri & 3 & $(4,5 \%)$ & 14 & $(21,2 \%)$ & 26 & $(39,4 \%)$ & 23 & $(34,8 \%)$ & 66 & $(100 \%)$ \\
\hline Noroeste de Minas & 1 & $(5,3 \%)$ & 10 & $(52,6 \%)$ & 3 & $(15,8 \%)$ & 5 & $(26,3 \%)$ & 19 & $(100 \%)$ \\
\hline Norte de Minas & 2 & $(2,2 \%)$ & 5 & $(5,6 \%)$ & 50 & $(56,2 \%)$ & 32 & $(36,0 \%)$ & 89 & $(100 \%)$ \\
\hline Rio Doce & 12 & $(11,8 \%)$ & 36 & $(35,3 \%)$ & 14 & $(13,7 \%)$ & 40 & $(39,2 \%)$ & 102 & $(100 \%)$ \\
\hline Triângulo Mineiro & 5 & $(14,3 \%)$ & 15 & $(42,9 \%)$ & 4 & $(11,4 \%)$ & 11 & $(31,4 \%)$ & 35 & $(100 \%)$ \\
\hline Zona da Mata & 49 & $(34,5 \%)$ & 56 & $(39,4 \%)$ & 5 & $(3,5 \%)$ & 32 & $(22,5 \%)$ & 142 & $(100 \%)$ \\
\hline Estado de Minas Gerais & 227 & $(26,6 \%)$ & 282 & $(33,1 \%)$ & 127 & $(14,9 \%)$ & 217 & $(25,4 \%)$ & 853 & $(100 \%)$ \\
\hline
\end{tabular}

Fonte: Elaboração própria com base em dados dos Censos Demográficos de 1991 e 2000.

Esses resultados deixam mais evidentes a "qualidade" do crescimento econômico ao longo do território mineiro. Por exemplo, analisando os municípios das macrorregiões Jequitinhonha/Mucuri, Norte e Noroeste de Minas, os resultados sugerem que é sobretudo pelo relativo menor impacto do crescimento sobre a renda dos muito pobres (até $40 \%$ mais pobres) que essas regiões apresentam uma relativa menor "qualidade" de seu crescimento econômico. Por sua vez, as macrorregiões Sul de Minas e Alto Paranaíba, por exemplo, apresentam uma relativa maior "qualidade" de crescimento, tendo em vista que a maioria de seus municípios apresenta um crescimento pró-pobre.

As evidências obtidas aqui estão consistentes com as estimativas obtidas para as elasticidades "pobreza-crescimen- 
to", indicando uma clara situação mais desfavorável para o Jequitinhonha/Mucuri, Norte e Noroeste de Minas. Por seu turno, mostra uma situação bem favorável para as regiões Sul de Minas e Alto Paranaíba.

De maneira geral, os resultados apresentados nesta seção indicam a existência de diferentes padrões de crescimento ao longo do território mineiro. Por exemplo, as macrorregiões do Norte de Minas e do Jequitinhonha/Mucuri apresentam características de crescimento econômico muito semelhantes a das microrregiões da região Nordeste do Brasil. As evidências apontadas por Silveira Neto (2005) a respeito da qualidade de crescimento das microrregiões do Nordeste brasileiro indicam que a menor elasticidade "pobreza-crescimento", ou seja, a relativa menor capacidade de reduzir a proporção de pobres para uma determinada taxa de crescimento, apresentada pela região nordestina, é explicada não apenas pela sua conhecida maior intensidade de pobreza (Rocha, 2005), mas também pelo relativo menor impacto do crescimento econômico sobre os mais pobres, isto é, pela "qualidade" de seu crescimento. De fato, essa caracterização do crescimen- to econômico nordestino pode também ser feita para o Norte de Minas e a região do Jequitinhonha/Mucuri. Ademais, Gonçalves e Silveira Neto (2007), ao analisarem os municípios nordestinos no período 1991-2000, também sugerem que o crescimento econômico no Nordeste apresenta pouca efetividade como um mecanismo de combate à pobreza na região, uma vez que ele impacta relativamente menos na renda dos mais pobres.

Evidências opostas as macrorregiões do Norte de Minas e do Jequitinhonha/Mucuri são encontradas, por exemplo, ao se analisar as macrorregiões do Alto Paranaíba e Sul de Minas. Os resultados encontrados com relação à qualidade de crescimento dessas duas regiões indicam uma grande elasticidade "pobrezacrescimento", ou seja, uma relativa maior capacidade de reduzir a proporção de pobres para uma determinada taxa de crescimento, que pode ser explicada não apenas pela sua menor intensidade de pobreza, mas também pelo relativo maior impacto do crescimento econômico municipal sobre os mais pobres, isto é, pela "qualidade" de crescimento de seus municípios. 


\section{4_ "Qualidade" do crescimento econômico e características socioeconômicas}

Neste artigo não se faz nenhuma estimação para verificar quais variáveis econômicas poderiam explicar tais desempenhos diferenciados em relação ao crescimento econômico. Essa tarefa deve ser explorada em artigos futuros em que o ferramental econométrico pode ser empregado a fim de encontrar resultados mais precisos e robustos. Entretanto, é importante analisar de maneira exploratória as características dos municípios enquadrados em cada um dos quatro padrões de crescimento verificados. ${ }^{23}$ A Tabela 7 faz uma descrição socioeconômica dos municípios por tipo de crescimento econômico descrito por Son (2004). A análise empreendida, valendo-se das evidências da Tabela 7, considera apenas o ano de 1991 tendo em vista a potencial endogeneidade com as variáveis em 2000. Ademais, foi incluída a taxa de crescimento da renda per capita entre 1991 e 2000, no intuito de salientar o padrão encontrado para essa variável.

Com base na Tabela 7, tem-se uma distinção clara entre os municípios que apresentaram um crescimento pró-pobre e os demais tipos de crescimento. ${ }^{24}$ De fato, os números apresentados para as variáveis socio-econômicas em 1991 permitem clara distinção entre os municípios com crescimento pró-pobre e os demais; os primeiros apresentam todos os indicadores sociais de 1991 em níveis superiores (exceto o índice de Gini). Essa evidência sugere que condições iniciais mínimas devem estar presentes para os mais pobres poderem tirar proveito do crescimento.

Em relação à taxa de crescimento da renda per capita entre 1991 e 2000, essa apresenta resultados dignos de nota. Os municípios com crescimento pró-pobre tiveram uma taxa 1,7 ponto percentual menor que aqueles municípios com um crescimento não pró-pobre, no período 1991-2000. Nesse ponto, surgem algumas limitações desse conceito de crescimento pró-pobre. Como bem colocado por Lopez (2004), em primeiro lugar, ao se dar um peso muito grande para a desigualdade, o resultado de uma política pública que é consistente com essa definição poderia levar a resultados subótimos, tanto para as famílias pobres quanto para as não-pobres.

Por exemplo, uma sociedade tentando alcançar um crescimento pró-pobre, com base nessa definição, preferiria um resultado caracterizado por um crescimento da renda média de $2 \%$ em que a renda média das famílias pobres crescesse em $3 \%$, em vez de um resultado em que o crescimento da renda média fosse de $6 \%$, mas a renda

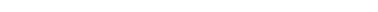

23 Crescimento pró-pobre, não pró-pobre, empobrecedor e inconclusivo.

24 A definição de crescimento pró-pobre menos estrita (i. e., fraca) foi utilizada para enquadrar os municípios em uma das quatro definições e com isso calcular as estatísticas. Vale ressaltar que as mesmas estatísticas foram geradas utilizando o conceito mais estrito de crescimento, sendo que os resultados obtidos foram bem semelhantes. 
das famílias pobres crescesse apenas 4\%. Enquanto o padrão de distribuição favorece as famílias pobres no primeiro cenário, tanto pobres quanto não-pobres estão melhores no segundo cenário. Em segundo lugar, essa definição pode favorecer intervenções do setor público que reduza a desigualdade não dando atenção aos seus impactos sobre o crescimento econômico. Evidentemente, pode-se argumentar que a outra definição de crescimento pró-pobre [o crescimento é pró-pobre se ele reduz a pobreza (Ravallion e Chen, 2003)] também tem alguns problemas. Por exemplo, um resultado caracterizado por crescimento médio de $6 \%$ com a renda dos pobres crescendo a meros $1 \%$ seria considerado pró-pobre.

Tabela 7_Descrição socioeconômica dos municípios por tipo de crescimento econômico

\begin{tabular}{|c|c|c|c|c|}
\hline & Pró-Pobre & Não Pró-Pobre & Empobrecedor & Inconclusivo \\
\hline Número de municípios & 227 & 282 & 127 & 217 \\
\hline $\begin{array}{l}\text { Percentual de indigentes em } 1991 \\
\text { (\% de pessoas com renda per capita abaixo de } \mathrm{R} \$ 37,75)\end{array}$ & 23,5 & 25,4 & 44,3 & 34,6 \\
\hline $\begin{array}{l}\text { Percentual de pobres em } 1991 \\
(\% \text { de pessoas com renda per capita abaixo de } \mathrm{R} \$ 75,50)\end{array}$ & 51,9 & 53,7 & 72,9 & 63,4 \\
\hline Renda per capita em $1991(\mathrm{R} \$)$ & 142,8 & 128,5 & 78,3 & 106,5 \\
\hline Taxa de crescimento da renda per capita em 1991-2000 & 4,1 & 5,4 & 3,7 & 4,1 \\
\hline Índice de Gini em 1991 & 0,56 & 0,52 & 0,51 & 0,54 \\
\hline Média de anos de estudo (pop. acima de 25 anos) em 1991 & 3,7 & 3,6 & 2,1 & 2,9 \\
\hline Taxa de analfabetismo (pop. acima de 15 anos em 1991 & 21,4 & 22,5 & 39,2 & 29,2 \\
\hline Mortalidade infantil em 1991 & 36 & 37 & 47 & 41 \\
\hline $\begin{array}{l}\text { Percentual de pessoas que vivem em domicílios } \\
\text { com água encanada em } 1991\end{array}$ & 77,6 & 72,6 & 35,9 & 57,0 \\
\hline $\begin{array}{l}\text { Percentual de pessoas que vivem em domicílios } \\
\text { com energia elétrica em } 1991\end{array}$ & 84,1 & 79,5 & 48,0 & 66,6 \\
\hline $\begin{array}{l}\text { Percentual de pessoas que vivem em domicílios urbanos } \\
\text { com serviço de coleta de lixo em } 1991 \ldots \ldots \ldots\end{array}$ & 61,9 & 55,0 & 25,0 & 40,1 \\
\hline
\end{tabular}

Fonte: Elaboração própria com base em dados dos Censos Demográficos de 1991 e 2000. Utilizou-se a média aritmética. 
Como dito anteriormente, existe uma distinção clara entre os municípios que apresentaram um crescimento pró-pobre e aqueles que apresentaram os outros padrões de crescimento. Os primeiros apresentam condições socioeconômicas iniciais, isto é, em 1991, superiores se comparados aos demais. Os municípios com crescimento pró-pobre apresentavam as menores taxas de indigência, de pobreza, mortalidade infantil e percentual de analfabetos em 1991. Por sua vez, os municípios que tinham, em 1991, maiores renda per capita, média de anos de estudo, percentual de domicilios com acesso a água encanada, com energia elétrica e com serviço de coleta de lixo, apresentaram um padrão de crescimento pró-pobre entre 1991 e 2000. Em suma, ao se analisar a Tabela 7 , verifica-se que as condições iniciais sugerem influenciar nos padrões de crescimento dos municípios mineiros na década de 1990.

Outra variável interessante de se analisar é o setor de atividade da população empregada, em 2000, por tipo de crescimento econômico. A Tabela 8 apresenta os dados. Com base na Tabela 8 , não é possível fazer uma distinção dos municípios que apresentaram um crescimento pró-pobre daqueles que apresentaram um crescimento não pró-pobre. Por outro lado, a diferenciação entre os municípios com crescimento pró-pobre e empobrecedor é clara. Em 2000, os municípios com crescimento empobrecedor apresentaram maior percentual $(56,6 \%)$ de traba- lhadores no setor agrícola (A) do que nos municípios em que o crescimento foi própobre $(37,8 \%)$. Por suas vez, nos setores da indústria de transformação (D), construção $(\mathrm{F})$, comércio $(\mathrm{G})$ e serviços domésticos $(\mathrm{P})$, são encontrados percentuais maiores nos municípios onde o crescimento foi pró-pobre em comparação aos municípios com crescimento empobrecedor.

\section{5_Conclusões}

Este trabalho, no período de 1991 a 2000, analisou relação entre crescimento econômico e pobreza do ponto de vista qualitativo. Em outras palavras, buscou-se analisar em que medida o crescimento econômico dos municípios mineiros tem se revelado um mecanismo relativamente eficaz de combate à pobreza do Estado.

Inicialmente, este estudo mostrou os diferenciais nas taxas de crescimento econômico das macrorregiões mineiras e dos municípios mineiros e a evolução da pobreza no período 1991-2000. Em seguida, valendo-se de dados dos municípios mineiros, forneceram-se evidências a respeito da elasticidade "pobreza-crescimento" e da "qualidade" do crescimento da renda per capita. Os resultados mostraram a diversidade do território mineiro. Foram encontradas regiões com municípios com boa qualidade de crescimento. 
Tabela 8_ Descrição do setor de atividade da população empregada em 2000 dos municípios por tipo de crescimento econômico

\begin{tabular}{|c|c|c|c|c|}
\hline & Pró-Pobre & Não Pró-Pobre & Empobrecedor & Inconclusivo \\
\hline Número de municípios (em quantidade) & 227 & 282 & 127 & 217 \\
\hline $\begin{array}{l}\text { A - de trabalhadores na Agricultura, Pecuária, Silvicultura } \\
\text { e Exploração Florestal em } 2000\end{array}$ & 37,8 & 37,3 & 52,9 & 42,6 \\
\hline B - de trabalhadores na Pesca em 2000 & 0,1 & 0,1 & 0,2 & 0,1 \\
\hline C - de trabalhadores nas Indústrias Extrativas em 2000 & 1,0 & 1,0 & 0,8 & 1,0 \\
\hline $\begin{array}{l}\text { D - de trabalhadores na Indústria de Transformação (Manufatura) } \\
\text { em } 2000\end{array}$ & 10,6 & 10,0 & 5,2 & 7,7 \\
\hline $\begin{array}{l}\text { E - de trabalhadores na Produção e Distribuição de Eletricidade, } \\
\text { Gás e Água em } 2000\end{array}$ & 0,3 & 0,4 & 0,3 & 0,3 \\
\hline F - de trabalhadores Construção em 2000 & 6,8 & 7,0 & 5,5 & 6,6 \\
\hline $\begin{array}{l}\text { G - de trabalhadores no Comércio; Reparação de Veículos } \\
\text { Automotores, Objetos Pessoais e Domésticos em } 2000\end{array}$ & 10,6 & 11,2 & 7,0 & 9,1 \\
\hline H - de trabalhadores na Indústria de Alimentação em 2000 & 3,3 & 3,5 & 2,3 & 3,1 \\
\hline $\begin{array}{l}\text { I- de trabalhadores em Transporte, Armazenagem } \\
\text { e Comunicações em } 2000\end{array}$ & 3,3 & 3,3 & 2,1 & 2,9 \\
\hline J - de trabalhadores em Intermediação Financeira em 2000 & 0,4 & 0,4 & 0,1 & 0,2 \\
\hline $\begin{array}{l}\text { K - de trabalhadores em Atividades Imobiliárias, Aluguéis } \\
\text { e Serviços Prestados às Empresas em } 2000\end{array}$ & 2,1 & 2,2 & 1,1 & 1,7 \\
\hline $\begin{array}{l}\text { L - de trabalhadores na Administração Pública, Defesa } \\
\text { e Seguridade Social em } 2000\end{array}$ & 5,2 & 4,8 & 5,2 & 5,6 \\
\hline M - de trabalhadores no setor de Educação em 2000 & 5,2 & 5,4 & 6,5 & 6,0 \\
\hline N - de trabalhadores no setor de Saúde e Serviços Sociais em 2000 & 1,7 & 1,8 & 1,1 & 1,6 \\
\hline $\begin{array}{l}\text { O - de trabalhadores em Outros Serviços Coletivos, Sociais } \\
\text { e Pessoais em } 2000\end{array}$ & 2,2 & 2,2 & 1,6 & 2,0 \\
\hline $\mathrm{P}-$ de trabalhadores em Serviços Domésticos em 2000 & 8,2 & 8,2 & 6,7 & 8,0 \\
\hline
\end{tabular}

Fonte: Elaboração própria com base em dados dos Censos Demográficos de 2000. Utilizou-se a média aritmética. 
Por exemplo, os municípios das macrorregiões do Alto Paranaíba e Sul de Minas tem grande elasticidade "pobrezacrescimento", ou seja, uma relativa maior capacidade de reduzir a proporção de pobres para uma determinada taxa de crescimento, resultado explicado não apenas pela sua menor intensidade de pobreza, mas também pelo relativo maior impacto do crescimento econômico municipal sobre os mais pobres, isto é, pela "qualidade" de crescimento de seus municípios.

Por outro lado existem regiões com uma má "qualidade" de crescimento econômico. As evidências encontradas para as macrorregiões do Norte de Minas e do Jequitinhonha/Mucuri apontam menor elasticidade "pobreza-crescimento", ou seja, uma relativa menor capacidade de reduzir a proporção de pobres para uma determinada taxa de crescimento, que pode ser explicada não apenas pela sua maior intensidade de pobreza, mas também pelo relativo menor impacto do crescimento econômico sobre os mais pobres, isto é, pela "qualidade" de seu crescimento.

Ademais, foram analisadas as características socioeconômicas dos municípios enquadrados em cada um dos quatro padrões de crescimento verificados. De maneira geral, existe uma distinção clara entre os municípios que apresentaram um crescimento pró-pobre e aqueles que apresentaram os outros padrões de crescimento.
Os municípios com crescimento pró-pobre apresentaram condições socioeconômicas iniciais, isto é, em 1991, superiores se comparados aos demais. Esse fato sugere que condições iniciais mínimas devem estar presentes para que os mais pobres possam tirar proveito do crescimento.

Por fim, é importante destacar o papel que as políticas de transferência condicionada de renda têm sobre o crescimento da renda dos mais pobres. No presente estudo, a década de análise foi a de 1990, período esse, em que tais políticas (quase) inexistiram. Por sua vez, nos anos seguintes a 2000 , houve grande aumento do gasto do governo federal em tais políticas, ultimamente chamada de Bolsa-Família. Ao se transferir renda diretamente aos mais pobres, tem-se um impacto imediato no crescimento da renda desse grupo da população, aumentando em grande medida a probabilidade que o padrão de crescimento seja considerado pró-pobre. Tal fato é ainda mais marcante em regiões onde a concentração de pobres é maior (por exemplo, na região Nordeste do Brasil, e nas macrorregiões Jequitinhonha/Mucuri e Norte de Minas). Dessa forma, as políticas de transferência condicionada de renda juntamente com os ganhos reais do salário mínimo nos últimos anos sugerem que o padrão de crescimento nos anos recentes apresenta um viés mais pró-pobre se comparado com os resultados da década de 1990. 


\section{Referências bibliográficas}

ALESINA, A.; RODRIK, D.

Distributive politics and economic growth. Quartely Journal of Economics, v. 108, p. 465-490, 1994.

\section{ATKINSON, A. B. On the} measurement of poverty. Econometrica, v. 55, p. 749-764, 1987.

BANGOLIN, I.; ÁVILA, R. Poverty distribution among the Brazilian states: a multidimensional analysis using capabilities and needs approaches. In. ENCONTRO NACIONAL DE ECONOMIA, 34., 2006, Salvador. Anais... Salvador: Anpec, 2006.

BARRO, R.; SALA-I-MARTIN, X. Economic growth. 2. ed. Cambridge, Mass.: MIT, 2003. 608p.

BARROS, R.; CARVALHO, M. Pobreza multidimensional no Brasil. In. ENCONTRO NACIONAL DE ECONOMIA, 34., 2006, Salvador. Anais... Salvador: Anpec, 2006.

BENABOU, R. Inequality and growth. NBER Working Paper 5658, 1996.

BDMG. Minas Gerais do século XXI. Belo Horizonte:

Rona, v. 10, 2002.
BIRDSALL, N.; LONDOÑO, J. L. Asset inequality matters: An assessment of the World Bank's Approach to poverty reduction. American Economic Review, v. 87 n. 2, p. 32-37, 1997a.

BIRDSALL, N.; LONDOÑO,

J. L. Asset inequality does matter: Lessons from Latin America. Office of the chief economist working paper. Inter-American Development Bank, 1997b.

BLOOM, D. E.; CANNING, D.; SEVILHA, J. The effect of health on economic growth: theory and evidence. Cambridge, Mass.: NBER, 2001. 26p. (Working Papers, 8587)

BRUNO, M.; RAVALLION, M.; SQUIRE, L. Equity and growth in developing countries:

Old and new perspectives on the policy issues. Policy Research Working Paper 1563, World Bank, Washington, DC, 1995.

CENSO DEMOGRÁFICO. Brasil. Rio de Janeiro: IBGE, 1991. (Disponível em CD-ROM).

CENSO DEMOGRÁFICO.

Brasil. Rio de Janeiro: IBGE, 2000. (Disponível em CD-ROM).
DEININGER, K.; SQUIRE, L. News ways of looking at old issues: Inequality and Growth. Journal of Development Economics, v. 57 , n. 2, p. 259-287, 1998.

DEININGER, K.; OLINTO, P. Asset distribution, inequality and growth. Policy Research Working Papers n. 2375, World Bank, 2000. DOLLAR, DAVID; AART, KRAAY. Growth is Good for the Poor. Journal of Economic Growth, v. 7, n. 3, p. 195-225, 2002.

GALOR, O.; ZEIRA, J. Income distribution and Macroeconomics. Review of Economics Studies, v. LX, p. 35-52, 1993

GONÇALVES, M. B. C.; SILVEIRA NETO, R. M. Crescimento pró-pobre nos municípios nordestinos:

Evidências para o período 1991-2000. In. ENCONTRO NACIONAL DE ECONOMIA, 35., 2007, Fortaleza. Anais... Fortaleza: Anpec, 2007.

GREENE, W. Econometric analysis. 5.ed. Upper Saddle River, N. J.: Prentice Hall, 2003. 1026p.

IPEA, PUND, FJP. Atlas do Desenvolvimento Humano no Brasil. Brasília, 2003.
IPEADATA. Dados macroeconômicos e regionais. Homepage < http://www. ipeadata.gov.br>

KAKWANI, N. Income inequality and poverty: Methods of estimation and policy applications. Oxford Univ. Press, New York, 1980

KAKWANI, N.; PERNIA, E. What is pro-poor growth. Asian Development Review, v. 16, n. 1, p. 1-22, 2000.

KUZNETS, S. Economic Growth and Income Inequality. American Economic Review, n. 45, p. $1-28,1955$

LIPTON, M.; RAVALLION, M. Poverty and policy. In: BEHRMAN, J.; SRINIVASAN, T. N. (Eds.). Handbook of Development Economics, v. 3, 1995. North Holland, Amsterdam.

LOPES, H.; MACEDO, P. B.; MACHADO, A. F. Indicador de pobreza: aplicação de uma abordagem multidimensional ao caso brasileiro. Belo Horizonte, 2003. (Texto para discussão, 223).

LOPEZ, J. H. Pro-poor growth: a review of what we know (and of what we don't). World Bank's PREM Poverty Group, 2004. 
MANKIW, N. G.; ROMER, D.; WEIL, D. N. A contribution to the empirics of economic growth. The Quarterly Journal of Economics, v. 107 , n. 2 , p. $407-437$, May 1992

PERSSON, T.; TABELLINI, G. Is inequality harmful for growth? American Economic Review, v. 84, p. 600-621, 1994.

PNUD. Metas do milênio. Brasília: Programa das Nações Unidas para o Desenvolvimento, 2005.

RAVALLION, M. Can high-inequality developing countries escape absolute poverty? Economic Letters, v. 53, p. 227-232, 1997.

RAVALLION, M. Growth, inequality and poverty: looking beyond averages. World Development, v. 29, n. 11, p. 1803-1815, 2001

\section{RAVALLION, M. Pro-poor} growth: a primer.

Policy research working papers n. 3242, World Bank, 2004.

RAVALLION, M.; DATT, G. When is growth pro-poor? Evidence from diverse experiences of India's states. Policy Research Working Papers n. 2263, World Bank, 1999.

RAVALLION, M.; DATT, G. Why has economic growth been more pro-poor in some states of India than others? Journal of Development Economics, v. 68, p. 381-400, 2002 .
RAVALLION, Martin; CHEN, Shaohua. What can new survey data tell Us about recent changes in distribution and poverty?

World Bank Economic Review, v. 11, n. 2, p. 357-382, 1997

RAVALLINON, M. \& CHEN, S. Measuring pro-poor growth. Economic Letters, v. 78 p. $93-99,2003$.

RIBEIRO, E. P.; COMIM F. V.; PORTO JUNIOR, S. S.

Crescimento pró-pobre no Brasil - uma análise exploratória, 2004. Mimeo.

ROCHA, S. Tendência evolutiva e características da pobreza no Rio de Janeiro. Texto para discussão do IPEA n. 536, 1995.

ROCHA, S. Pobreza no Brasil, afinal de que se trata? Rio de Janeiro: FGV, 2005.

SEN, A. Development as Freedom. New York: Anchor Books, 2000. SHORROCKS A.; HOVEN R. Growth, inequality and poverty: Prospects for pro-poor economic development. Ed.: Oxford, 2005.

SILVEIRA NETO, R. M. Quão pró-pobre tem sido o crescimento econômico no nordeste? Evidências para o período 1991-2000. In. ENCONTRO REGIONAL DA ANPEC NORDESTE, 10., 2005, Fortaleza. Anais... Fortaleza: Anpec, 2005

SOLOW, R. M. A contribution to the theory of economic growth. Quarterly Journal of Economics, v. 70, n. 1, p. 65-94, Feb. 1956.
SON, H. H. A note on pro-poor growth. Economic Letters, v. 82, p. 307-314, 2004.

WHITE, H.; ANDERSON, A.

Growth vs. redistribution:

Does the pattern of growth matter? DFID white paper on eliminating World Poverty: making globalization Work for the Poor, 2000.

WORLD BANK. World development report: attacking poverty. New York: Oxford University Press. 2000.

. . . . . . . . . . . . .

- O autor agradece aos dois

- pareceristas anônimos pelas - sugestões e contribuições para a - melhoria do texto. Os erros

- remanescentes são do autor. :

E-mail de contato do Autor

guilherme.resende@ipea.gov.br

- Artigo recebido em abril de 2007

aprovado em fevereiro de 2008.

.............. 
Anexo

Mapa 1_ Divisão macrorregional de Minas Gerais e municípios com mais de $\mathbf{1 0 0 . 0 0 0 ~ h a b i t a n t e s ~}$

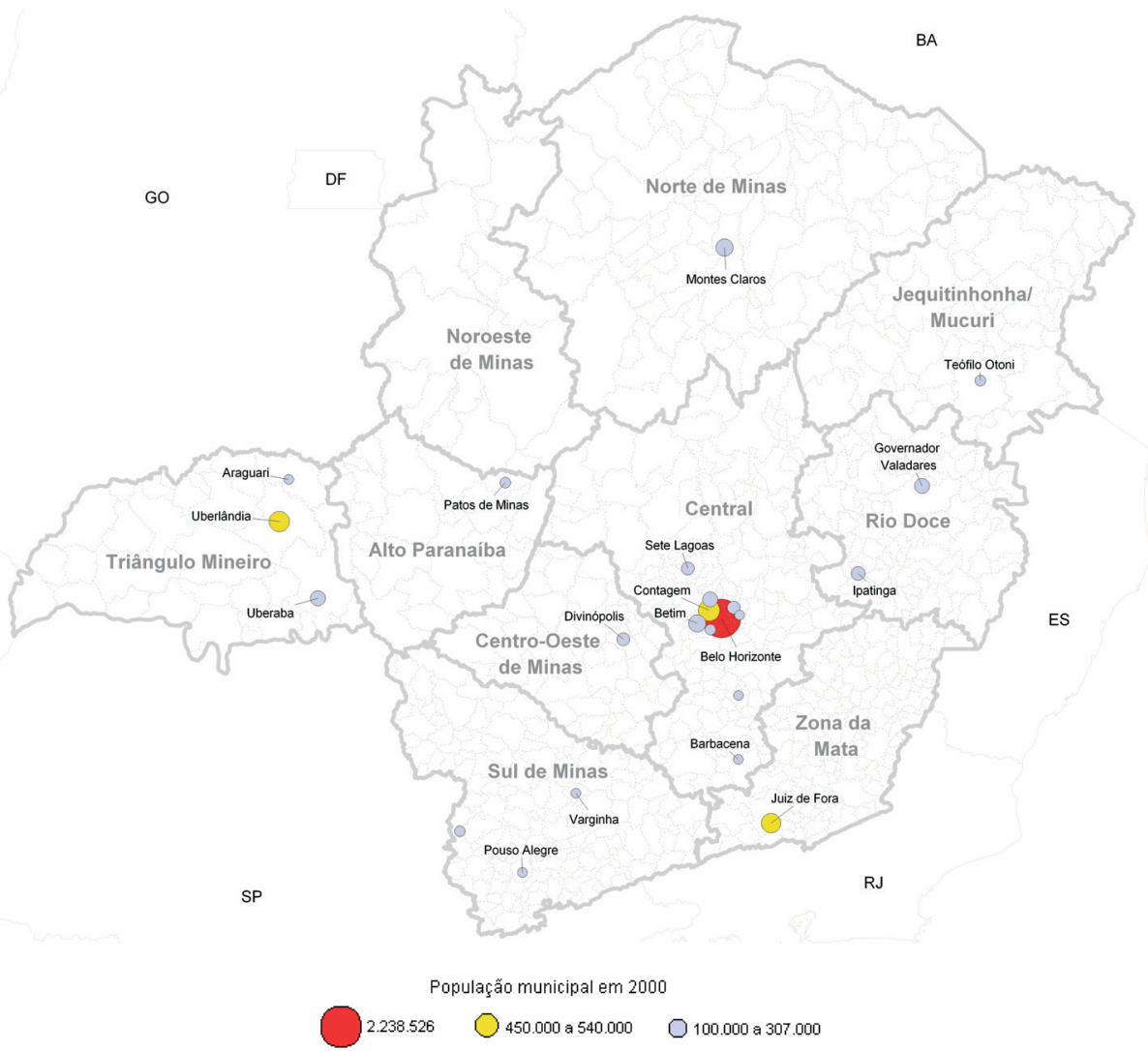

Fonte: Elaboração própria com base em dados dos Censos Demográficos de 2000. 


\section{Mapa 2_ Percentual de indigentes em 1991 e 2000 nos municípios mineiros}
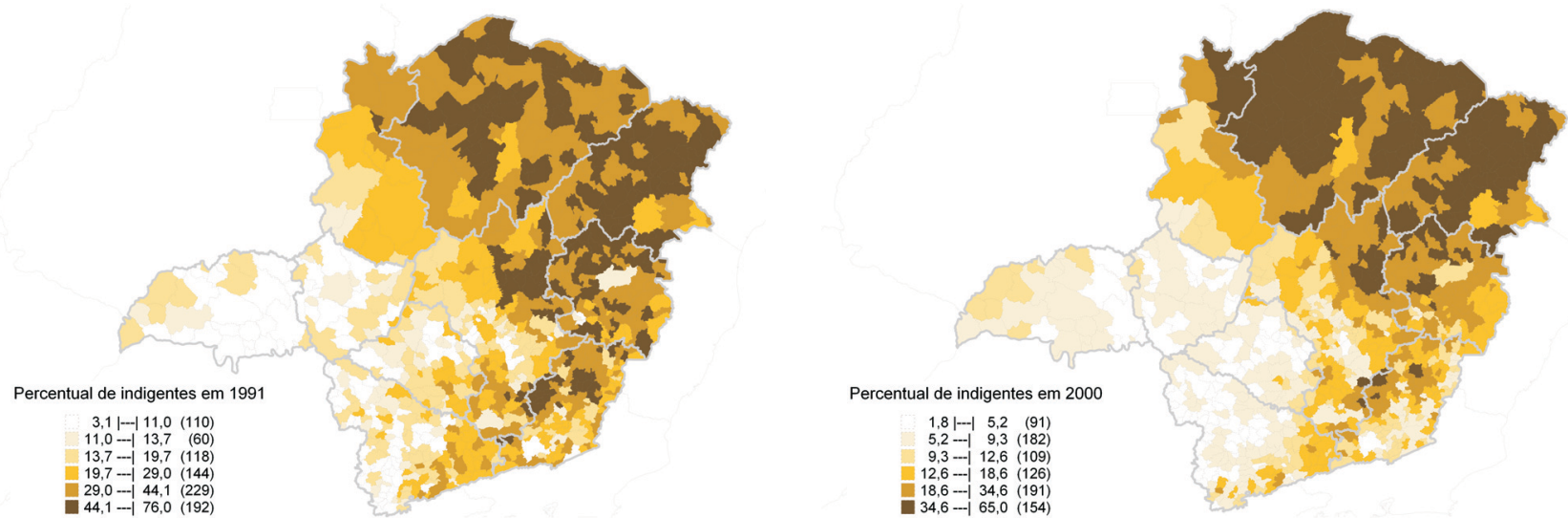

Fonte: Mapas feitos pelo autor com dados do Censo de 1991 e 2000

$\left.{ }^{*}\right)$ Entre parênteses, nas legendas, número de municípios em cada intervalo de percentual de indigentes;

(**) Nas legendas, os intervalos foram definidos com base nos dados da Tabela 1.

\section{Mapa 3_Percentual de pobres em 1991 e 2000 nos municípios mineiros}
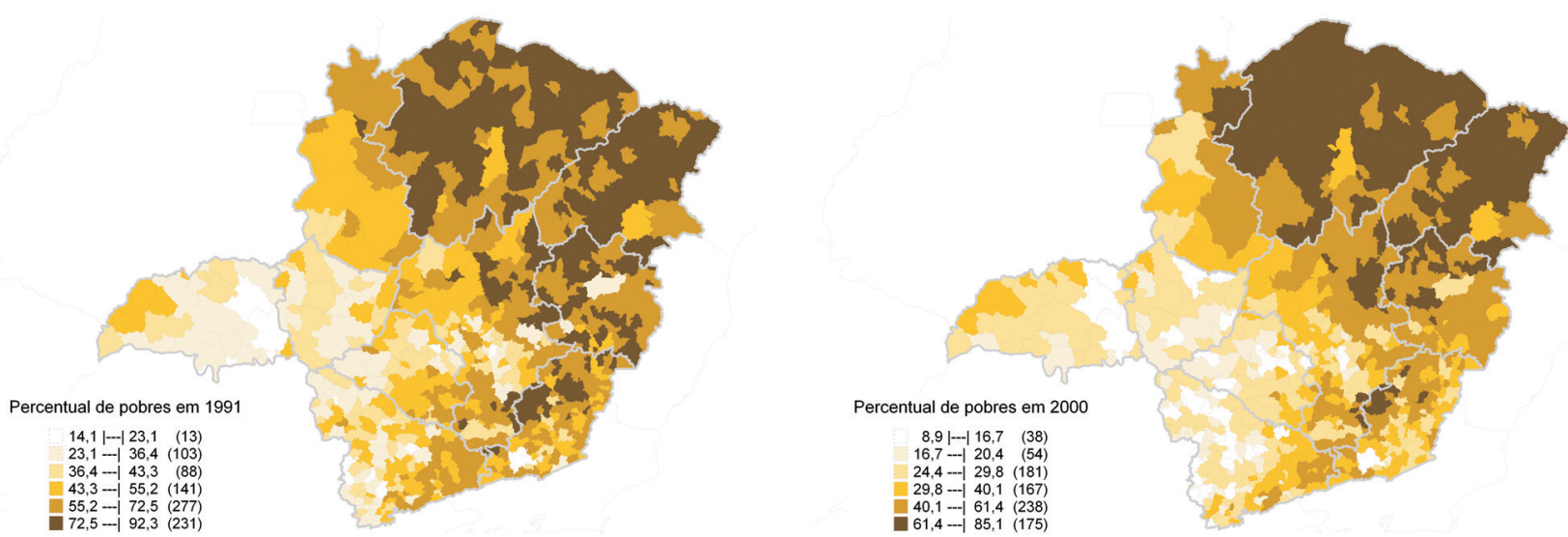

Fonte: Mapas feitos pelo autor com dados do Censo de 1991 e 2000.

(*) Entre parênteses, nas legendas, número de municípios em cada intervalo de percentual de pobres;

${ }^{* *}$ Nas legendas, os intervalos foram definidos com base nos dados da Tabela 1. 
Mapa 4_ "Qualidade" do crescimento econômico nos municípios do Estado de Minas Gerais 1991-2000

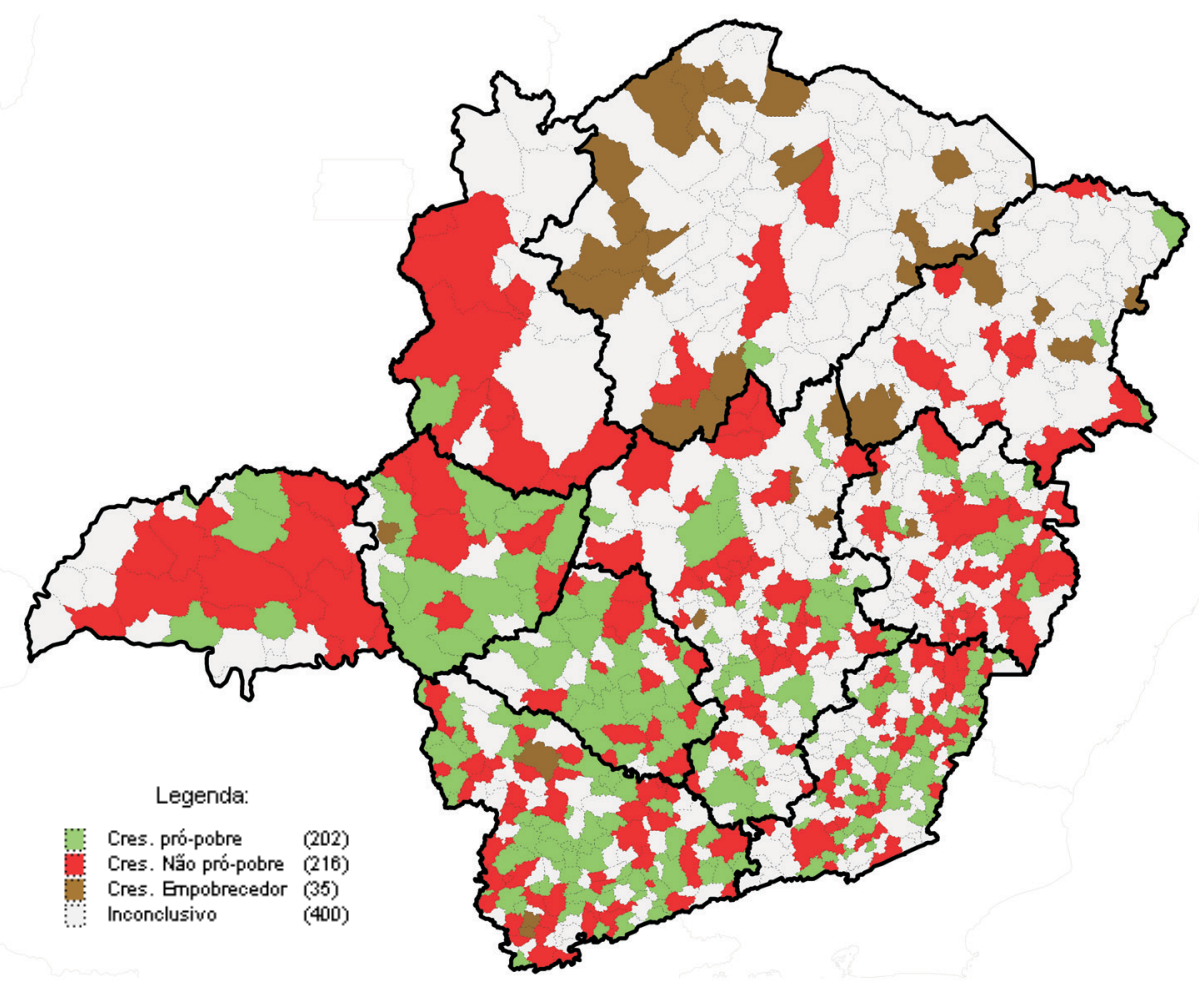

Fonte: Elaboração própria com base em dados dos Censos Demográficos de 1991 e 2000.

Obs.: Na legenda, entre parênteses, número de municípios de acordo com a "qualidade" do crescimento econômico. 
Mapa 5 "Qualidade" do crescimento econômico nos municípios do Estado de Minas Gerais 1991-2000 (Conceito menos estrito)

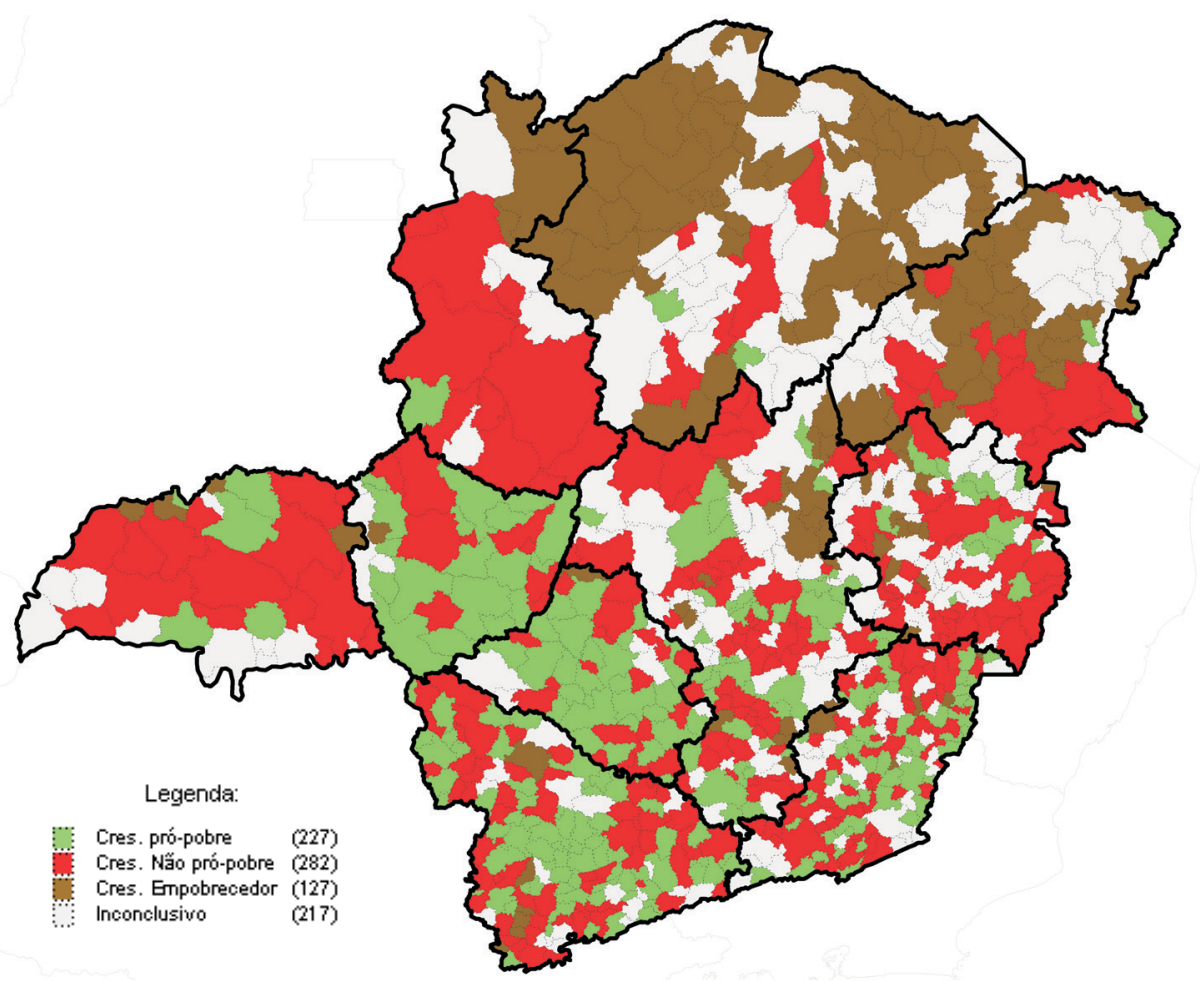

Fonte: Elaboração própria com base em dados dos Censos Demográficos de 1991 e 2000.

Obs.: Na legenda, entre parênteses, número de municípios de acordo com a "qualidade" do crescimento econômico (conceito menos estrito). 